\title{
Two decades of SPECT/CT - the coming of age of a technology: An updated review of literature evidence
}

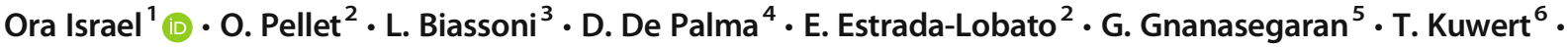 \\ C. la Fougère ${ }^{7} \cdot$ G. Mariani ${ }^{8} \cdot$ S. Massalha ${ }^{9,10} \cdot$ D. Paez ${ }^{2} \cdot$ F. Giammarile ${ }^{2}$
}

Received: 6 March 2019 / Accepted: 14 June 2019 / Published online: 4 July 2019

(C) The Author(s) 2019

\begin{abstract}
Purpose Single-photon emission computed tomography (SPECT) combined with computed tomography (CT) was introduced as a hybrid SPECT/CT imaging modality two decades ago. The main advantage of SPECT/CT is the increased specificity achieved through a more precise localization and characterization of functional findings. The improved diagnostic accuracy is also associated with greater diagnostic confidence and better inter-specialty communication.

Methods This review presents a critical assessment of the relevant literature published so far on the role of SPECT/CT in a variety of clinical conditions. It also includes an update on the established evidence demonstrating both the advantages and limitations of this modality.

Conclusions For the majority of applications, SPECT/CT should be a routine imaging technique, fully integrated into the clinical decision-making process, including oncology, endocrinology, orthopaedics, paediatrics, and cardiology. Large-scale prospective studies are lacking, however, on the use of SPECT/CT in certain clinical domains such as neurology and lung disorders. The review also presents data on the complementary role of SPECT/CT with other imaging modalities and a comparative analysis, where available.
\end{abstract}

Keywords SPECT/CT $\cdot$ Oncology $\cdot$ Endocrinology $\cdot$ Infection $\cdot$ Orthopaedics $\cdot$ Paediatrics $\cdot$ Cardiopulmonary

\section{Introduction}

The advent of positron emission tomography (PET) combined with computed tomography (CT), namely PET/CT, generated great excitement and anticipation in the imaging community. A publication released less than a decade after its introduction [1] envisaged a soon-to-come scenario where wide availability of positron-emitting radiopharmaceuticals would virtually

This article is part of the Topical Collection on Technology.

Electronic supplementary material The online version of this article (https://doi.org/10.1007/s00259-019-04404-6) contains supplementary material, which is available to authorized users.

Ora Israel

o_israel@rambam.health.gov.il

1 Rappaport School of Medicine, Israel Institute of Technology, Haifa, Israel

2 Nuclear Medicine and Diagnostic Imaging Section International Atomic Energy Agency, Vienna, Austria

3 Department of Radiology, Great Ormond Street Hospital for Children NHS Foundation Trust, London, UK

4 Nuclear Medicine Unit, Circolo Hospital, ASST-Settelaghi, Varese, Italy
5 Department of Nuclear Medicine, Royal Free NHS Foundation Trust, London, UK

6 Clinic of Nuclear Medicine, University Hospital, Erlangen, Germany

7 Division of Nuclear Medicine and Clinical Molecular Imaging, Department of Radiology, University Hospital, Tubingen, Germany

8 Regional Center of Nuclear Medicine, University of Pisa, Pisa, Italy

9 Department of Medicine, University of Ottawa Heart Institute, Ottawa, Canada

10 Department of Nuclear Medicine, Rambam Healthcare Campus, Haifa, Israel 
replace all single-photon-emitting agents, making conventional planar and tomographic imaging obsolete. Ten years after that dismal forecast, we are witnessing an era of revived interest in single-photon imaging. The continuing evolution of technology and expertise in the field takes advantage of the full synergism between single-photon and positron emission imaging [2], while also continuing the debate regarding the optimal strategies for managing the wealth of clinically relevant information that can be obtained [3]. Hybrid imaging, including single-photon emission computed tomography (SPECT) combined with computed tomography (CT), SPECT/CT, translates molecular and metabolic information into an immediate clinical impact for a wide range of diseases. Scintigraphy is characterized by an inherent high sensitivity and negative predictive value (NPV), enhanced by SPECT. With the addition of CT, SPECT/CT further improves the diagnostic accuracy, specificity, and positive predictive value (PPV) of nuclear medicine studies. The use of SPECT/CT is rising in frequency and spreading to new clinical settings. Recent trends in sales of new nuclear medicine equipment confirm that installations of SPECT/CT devices exhibit a steep surge worldwide [4].

The value of SPECT/CT towards improved staging, prognosis and treatment planning and monitoring for a wide variety of diseases, as published up to 2008-2009, have been reviewed when SPECT/CT was just coming out of its infancy stage [5]. Over the last decade, significant advances in technology have taken place, and literature evidence has continued to accumulate. For these reasons, it was deemed appropriate to undertake an up-to-date review of the current uses of SPECT/ CT, not only as a problem-solving approach, but also, and most importantly, as a diagnostic tool fully integrated into the clinical approach. More than 400 publications have been reviewed for this purpose. The complex technological issues involved in the use of SPECT/CT, such as novel radiopharmaceuticals, hardware, image acquisition protocols, quantitation, and dosimetry and radiation exposure, are beyond the scope of the current review.

\section{Oncology applications}

SPECT/CT has found its way into most clinical scenarios in patients with malignancies who undergo tests performed with single-photon-emitting tracers. The availability of both functional and structural data has resulted in a proven synergistic effect on the diagnostic potential in the assessment of cancer. Modern SPECT/CT devices are equipped with a CT component with diagnostic capabilities. This provides the potential to enhance the value of this modality for assessment of tumours by performing a contrast-enhanced CT (ceCT) as part of the hybrid study. While currently not routinely performed or even recommended for SPECT/CT, this warrants further consideration based on the strong evidence accumulated for PET/CT. Current clinical applications of SPECT/CT in cancer need to be reviewed, keeping in mind that PET/CT alternatives are available in many centres, and choosing the most beneficial procedure for the individual patient is imperative.

\section{Sentinel lymph node mapping}

Detection of lymphatic metastatic involvement is important in the staging, prognosis and treatment of various malignancies. Following interstitial radiocolloid injection at the site of the primary tumour, scintigraphy visualizes its lymphatic drainage. The term "sentinel lymph node" (SLN) is used to describe the first lymph node (LN) encountered by lymphatic vessels draining the primary tumour. Lymphatic drainage is complex, and SPECT/CT can achieve accurate pre-surgical SLN mapping, with further implementation into a personalized surgical approach [6].

In breast cancer, where SLN mapping is well validated, a literature search yielded 41 articles on SPECT/CT, 16 of which were retained for analysis (Fig. 1, Online Table 1).

Similarly, SLN mapping has been validated in patients with intermediate-thickness melanoma. A literature search yielded 19 out of 54 articles about SPECT/CT in melanoma that were retained for analysis (Online Table 2).

In early-stage head and neck malignancies, SLN biopsy is increasingly used for treatment stratification, being associated with decreased morbidity and better outcomes as compared to elective neck dissection $[7,8]$. The addition of SPECT/CT to dynamic lymphoscintigraphy in oral carcinoma revealed additional SLNs in $22 \%$ patients, providing new anatomical information in $3 \%$ of patients, for an overall detection rate for the combined approach of $98 \%[8,9]$.

In gynaecological cancers, SLN mapping using SPECT/CT facilitates intraoperative SLN biopsy in cancer of the cervix $[10,11]$ and vulva $[12,13]$. SPECT/CT localization of SLNs was found to be anatomically accurate in $91 \%$ of endometrial tumours, a malignancy with a low prevalence of nodal metastases [14]. One prospective study demonstrated the value of SPECT/CT in penile cancer, improving both the LN detection rate and their precise localization in drainage basins [15].

\section{Thyroid cancer}

Recent guidelines [16] present the optimal modalities for differentiated thyroid cancer (DTC) management. The selection of patients for post-surgical radioiodine (RAI) ablation is based on clinical and histopathologic risk stratification [17-20]. RAI whole-body scintigraphy (WBS) at the completion of ablation can change the risk stratification [18]. SPECT/ CT provides additional information, mainly by clarifying equivocal planar findings (Fig. 2) [19]. RAI-SPECT/CT has been compared with RAI-WBS at various stages of DTC, 


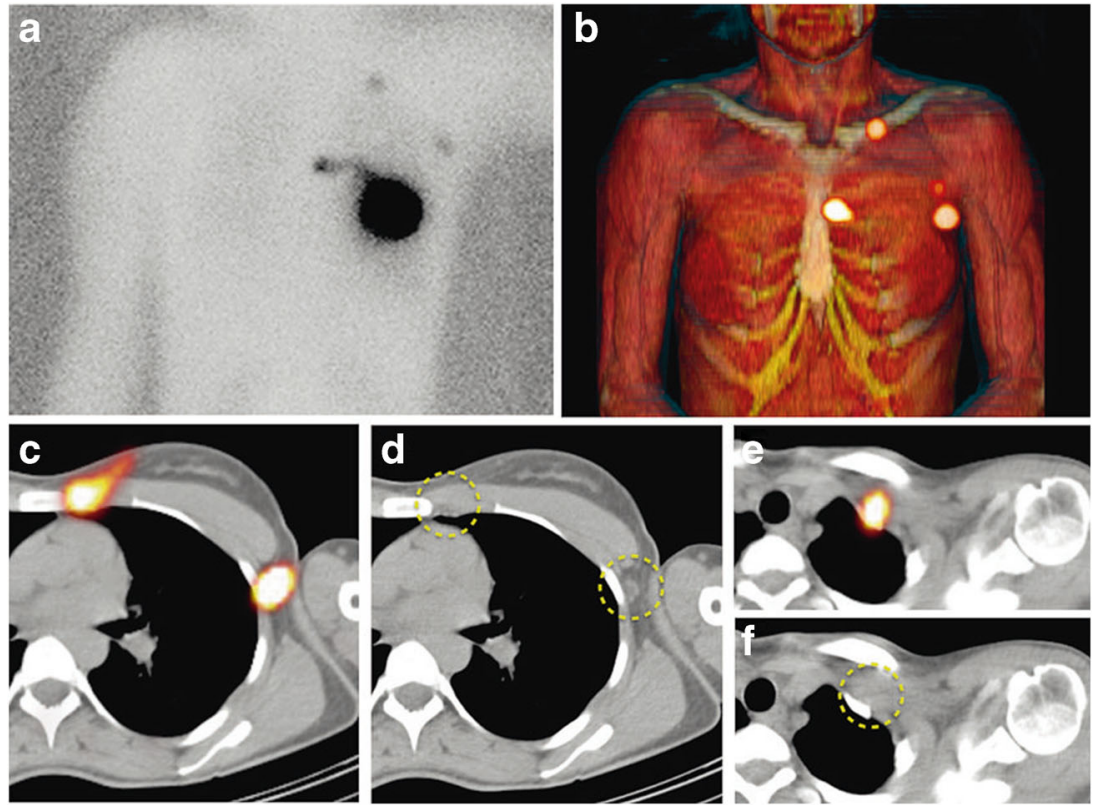

Fig. $1^{99 \mathrm{~m}} \mathrm{Tc}-\mathrm{nanocolloid} \mathrm{SPECT} / \mathrm{CT}$ in sentinel node lymphoscintigraphy. Preoperative sentinel lymph node (SLN) mapping in a 63-year-old woman with cancer of the left breast following intratumoral injection of ${ }^{99 \mathrm{~m}} \mathrm{Tc}$-nanocolloidal albumin. Planar imaging with body contouring (a), with a ${ }^{57} \mathrm{Co}$ flood source beneath the patient's body, visualizes lymphatic drainage to SLNs in the left axilla, periclavicular area, and internal mammary chain. 3D surface volume rendering SPECT/CT (b) identifies the anatomical correlates of the
SLNs localized on transaxial SPECT/CT and CT slices to the second intercostal space and level I of the left axilla, respectively $(\mathbf{c}, \mathbf{c})$, as well as behind the left clavicle (e, f), as indicated by dashed yellow circles. [Reproduced with permission from: Giammarile F, Orsini F, Valdés Olmos RA, Vidal-Sicart S, Giuliano AE, Mariani G. Radioguided surgery for breast cancer. In: Strauss HW, Mariani G, Volterrani D, Larson SM, Eds. Nuclear Oncology - From Pathophysiology to Clinical Applications. New York: Springer; 2017:1363-1400] including pre- and post-ablation, and after therapy for recurrent or metastatic disease.

Prior to ablation, RAI-SPECT/CT identified unexpected cervical nodal metastases in $30-44 \%$ and distant lesions in $4-10 \%$ of cases, leading to a change in management in 30 $60 \%$ of patients, mostly receiving higher RAI treatment doses than initially planned (Online Table 3) [21-24]. After ablation, SPECT/CT was significantly more specific than WBS with or without SPECT, showing a definite incremental value in $42 \%$ of cases [25]. In multiple studies involving large numbers of patients, SPECT/CT correctly characterized over $90 \%$ of equivocal RAI foci seen on WBS, and detected additional, cervical LNs or distant metastases in $9-40 \%$ of cases. This resulted in modification of the TNM stage on average in $10 \%$, the risk category in $35 \%$, and planned management in up to $15 \%$ of patients [26-39]. Post-ablation RAI-SPECT/CT has also been used for radiation dosimetry estimates [40].

After RAI treatment for recurrent or metastatic DTC, SPECT/CT provided important information in $73.9 \%$ of cases and led to a change in management in $47.1 \%$ of patients [41]. SPECT/CT detected unexpected nodal neck metastases in $83.1 \%$, lung metastases in $15.5 \%$, and bone lesions in $2.8 \%$ of patients [42]. Pretreatment ${ }^{124} \mathrm{I}$-iodide PET/CT and posttherapy SPECT/CT were in agreement in $97 \%$ of lesions [43]. A lesion-based comparison of pretreatment $\left[{ }^{18} \mathrm{~F}\right]$ fluorodeoxyglucose (FDG) PET/CT with pre- and post- treatment RAI-SPECT/CT and WBS showed that pretreatment SPECT/CT performed better than planar WBS or $\left[{ }^{18} \mathrm{~F}\right] \mathrm{FDG}$ PET/CT, while post-therapy SPECT/CT performed better than WBS but worse than $\left[{ }^{18} \mathrm{~F}\right] \mathrm{FDG}$ PET/CT [44]. SPECT/CT had a definite diagnostic impact in an average of $57 \%$ of DTC patients (Online Table 4). It detected unexpected sites of cervical LN or distant metastases in about $25 \%$ of patients, thus up- or down-staging over $20 \%$ and leading to change in planned management in about $25 \%$ of patients. [45-51].

\section{Neuroendocrine neoplasms}

Neuroendocrine neoplasms (NENs) are a heterogeneous group of tumours originating from single or clustered neuroendocrine cells, located in the gastrointestinal tract (GIT) and lungs and less commonly in the thymus, adrenal medulla, and the pituitary, parathyroid and thyroid glands. Having a nonspecific clinical presentation, NENs represent a diagnostic and therapeutic challenge. The European Neuroendocrine Tumour Society (ENETS) diagnostic and prognostic stratification criteria used in the management decision process are based on histological typing, differentiation, grading, and TNM staging. Imaging plays a fundamental role in the diagnosis, staging, treatment selection, and follow-up of NENs. Specifically, scintigraphy of tumour somatostatin receptor 
Fig. 2 Post-ablation ${ }^{131}$ I-iodide SPECT/CT in differentiated thyroid cancer (DTC). A 48-yearold woman after thyroidectomy and lymphadenectomy for DTC (18 mm, infiltrating the thyroid parenchyma and capsule), with intravascular tumour emboli and nodal metastases found at surgery, stage pT1bN1bMx. The patient received $2.96 \mathrm{GBq}^{131}$ I-iodide treatment. Planar post-ablation

${ }^{131}$ I-iodide scan (a) shows multiple sites of intense uptake in the neck and upper mediastinum consistent with known metastatic spread. There is an additional area of focal tracer accumulation of moderate intensity in the right pelvis (arrow). SPECT/low-dose CT slices and maximum intensity projection (MIP) image of the pelvis (b) locate this uptake to the lower portion of the ascending colon, consistent with physiologic tracer excretion. SPECT/CT excluded the presence of an additional malignant site in an equivocal finding detected on planar scintigraphy. [Images provided courtesy of Drs. Paola A. Erba and Roberta Zanca, Regional Center of Nuclear Medicine, University of Pisa, Italy]
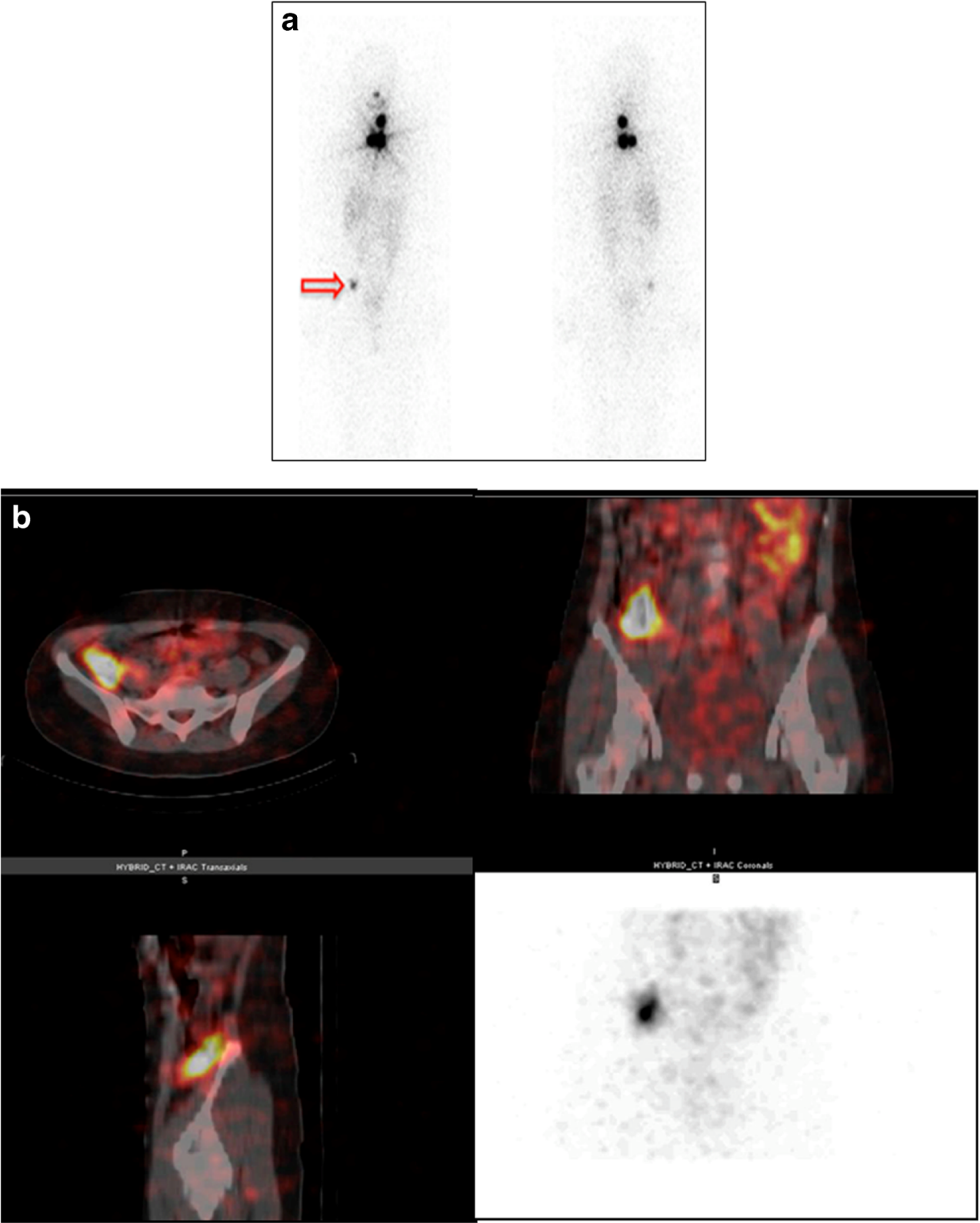

(SSR) expression or catecholamine uptake aims to identify functionally active lesions and has theragnostic potential. SPECT/CT has demonstrated an incremental value for assessment of NENs (Fig. 3), with a literature search yielding a total of 30 articles, 26 of which were retained for further analysis (Online Table 5). Radiolabelled octreotide scintigraphy has been used for assessment of SSR-positive NENs [52-62] with the addition, in recent years, of PET/CT with ${ }^{68} \mathrm{Ga}$-labelled somatostatin analogues. Catecholamine metabolism is assessed with ${ }^{123}$ I-metaiodobenzylguanidine (mIBG), ${ }^{18} \mathrm{~F}$ DOPA, and potentially [ $\left.{ }^{11} \mathrm{C}\right] 5$-hydroxytryptophan (5-HTP). While the use of PET/CT is associated with higher diagnostic accuracy, better patient compliance and comfort, and lower radiation exposure, the use of SPECT/CT has a proven incremental value in the assessment of NENs (Online Table 5).

\section{Bone metastases}

Bone metastases are associated with worse prognosis and decreased survival $[63,64]$. Bone scintigraphy (BS) detects metastases in the presence of a reactive increase in bone formation. CT visualizes osseous metastases as a difference in density relative to normal tissue. Literature evidence on the diagnostic accuracy of BS in cancer is of low quality, hampered by the lack of a gold standard. Sensitivity ranges between $85 \%$ and 96\% [64-66], limited by spatial resolution of planar and SPECT studies [67]. BS does not detect small osseous metastases unless they exhibit high uptake, such as in prostate cancer. Purely lytic metastases, such as in renal cancer or lymphoma, as well as predominantly lytic lesions in breast cancer, are difficult to detect by BS. These lesions can be detected on 


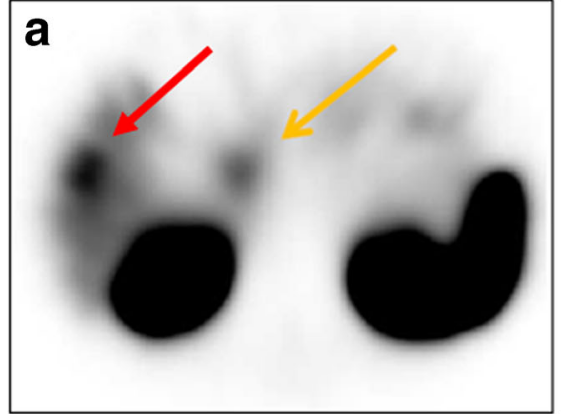

Fig. $3{ }^{111}$ In-somatostatin SPECT/CT in neuroendocrine neoplasms. A 34-year-old patient with biochemical suspicion of NEN and a lesion in the head of pancreas on CT was referred for ${ }^{111} \mathrm{In}$-somatostatin scintigraphy for staging. SPECT (a) shows two foci of intense tracer

the CT component of SPECT/CT, thus enhancing the study sensitivity. Bone metastases can also be efficiently detected using FDG PET/CT, an imaging modality that plays an important role in assessing skeletal involvement in cancer, especially in the case of lesions with a predominantly osteolytic rather than osteoblastic pattern [63]. The specificity of BS for detection of bone metastases is low, since multiple benign conditions show increased radiotracer uptake, thus requiring a differential diagnosis [68]. However, since most benign conditions have a typical appearance on $\mathrm{CT}$, the combined information provided by SPECT/CT adds specificity to BS in the assessment of skeletal involvement in malignant diseases.

A literature search yielded 104 articles about bone SPECT/CT in malignancies, of which 20 were further analysed. SPECT/CT was able to characterize most equivocal findings on BS, planar and/or SPECT, in cancer patients (Fig. 4) [69-71]. Despite the heterogeneity

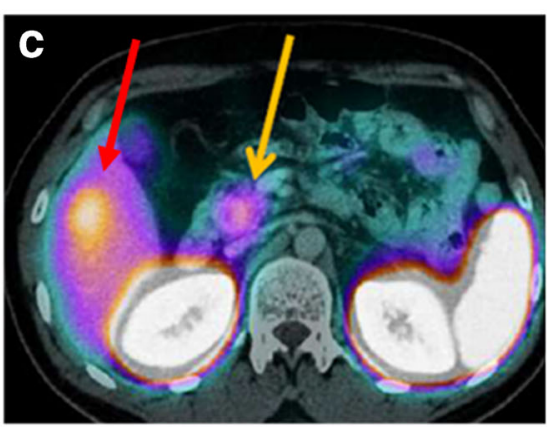

uptake in the upper abdomen, localized by contrast-enhanced CT (b) to a hypervascular primary lesion in the head of the pancreas and an isodense metastasis in the right lobe of the liver (arrows), confirmed on SPECT/CT (c)

of the studies, the results are remarkably consistent. SPECT/CT characterized $66.7-100 \%$ of equivocal findings, for an average rate of $85.3 \%$, in 826 lesions. A comparison of sensitivity and specificity of SPECT/CT to other modalities $[69,71-78]$ (Online Table 6) showed its lower performance vs. whole-body (WB)-MRI [69] and conflicting results vs. ${ }^{18} \mathrm{~F}$-fluoride PET/CT [69, 77]. A new perspective for skeletal scintigraphy is WBSPECT/CT substituting for planar BS. WB-SPECT/CT demonstrated higher sensitivity and similar specificity to WB-planar and one-field-of-view (FOV)-positiontargeted SPECT/CT [79], but with only limited incremental diagnostic value for 2 -FOV vs. 1 -FOV bone SPECT/CT [80]. It seems reasonable to predict that WB-SPECT/CT will be the future of BS in cancer patients, in particular when fast acquisition protocols become widely available [81].

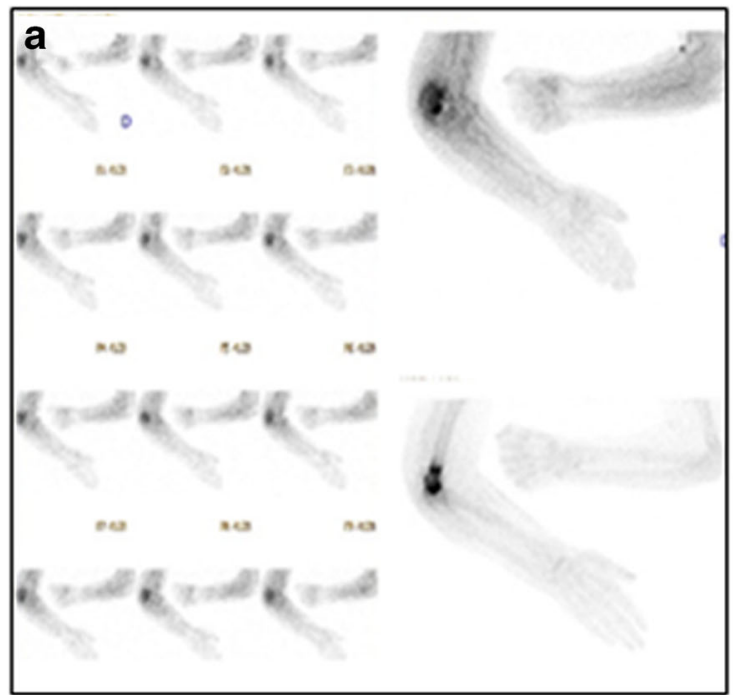

Fig. $4{ }^{99 \mathrm{~m}} \mathrm{Tc}$-DPD bone SPECT/CT in a patient with renal cancer and bone pain. A 62-year-old patient with renal cancer was referred for evaluation of painful left elbow. Early planar scan of the elbows (a) shows intense hyperaemia on the left side. Delayed whole-body
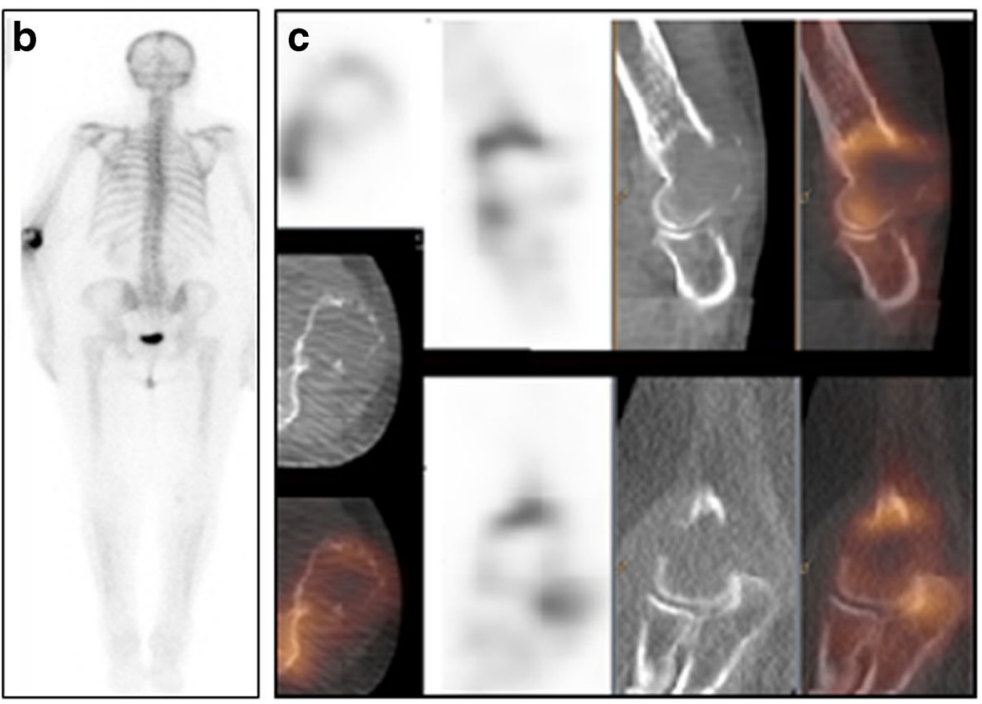

scintigraphy ( $b$, posterior view) demonstrates intense inhomogeneous focal uptake in the distal part of the left humerus, localized by SPECT/ CT (c) to an osteolytic metastasis seen on the CT component 


\section{Prostate cancer}

The development of PET radioligands directed against the prostate-specific membrane antigen (PSMA) has revolutionized the diagnostic workup of prostate cancer $[82,83] .{ }^{99 \mathrm{~m}} \mathrm{Tc}-$ labelled PSMA-ligand agents have also recently been developed [84-88]. SPECT/CT with ${ }^{99 \mathrm{~m}}$ Tc-MIP 1404 (PSMA-ligand subtype) enabled the detection of small LNs or additional metastases (Fig. 5). SPECT/CT achieved sensitivity of up to $97 \%$ for diagnosis of primary prostate cancer $[89,90]$. In a group of 225 patients with biochemical relapse, the detection rate correlated with prostate-specific antigen (PSA) levels [91]. PSMA-SPECT/CT also demonstrated higher sensitivity than BS with SPECT/CT and MRI for the detection of skeletal metastases in patients with biochemical recurrence of prostate cancer [92]. However, a small comparative study in 14 patients showed the superiority of ${ }^{68} \mathrm{Ga}-\mathrm{PSMA}-\mathrm{PET} / \mathrm{CT}$ over ${ }^{99 \mathrm{~m}} \mathrm{Tc}-\mathrm{HYNIC}$ PSMA-SPECT/CT for detection of malignant sites [93].

\section{Transarterial radioembolization}

The liver represents a frequent site of primary cancer and metastatic disease. Transarterial radioembolization
(TARE) uses percutaneous intra-arterial techniques to inject micron-sized embolic particles, ${ }^{90} \mathrm{Y}$ - or more recently ${ }^{166} \mathrm{Ho}$-microspheres, for treatment of malignant liver lesions. Beta irradiation favours destruction of the tumour cells surrounding microvessels with high radioactive particle concentration. The supply of blood to hepatic tumours derives mainly from the arterial circulation, and therefore, delivery of radioactive compounds into the hepatic artery can achieve highly selective tumour uptake. The disadvantages of TARE are related to potential inadvertent delivery or shunting.

A pre-therapy angiographic evaluation combined with scintigraphy following intra-arterial ${ }^{99 \mathrm{~m}} \mathrm{Tc}$-labelled albumin macroaggregate injection maps the tumour-feeding vessels, quantifies potential liver-to-lung shunting, and can detect the presence of blood reflux to the bowel, stomach, or pancreas. A pre-therapeutic SPECT/CT can better assess intra- and extrahepatic distribution of the radiotracer and can be used as an adjunct to calculate the therapeutic dose. After ${ }^{90} \mathrm{Y}$-microsphere administration, post-therapeutic bremsstrahlung SPECT/CT can verify the sphere distribution and enable post-treatment dosimetry. A literature search yielded 15 of 74 articles, focused mainly on dosimetry, that were retained for analysis (Online Table 7).

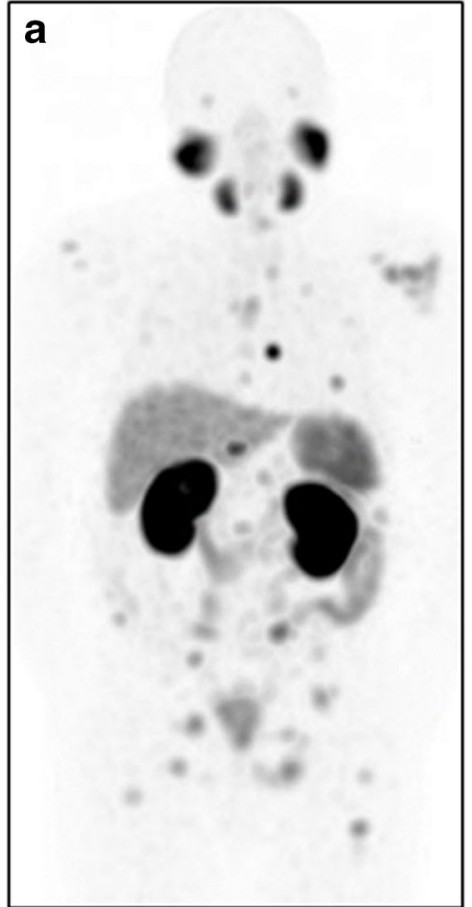

Fig. $5{ }^{99 \mathrm{~m}} \mathrm{Tc}-\mathrm{MIP}-1404$ PSMA-SPECT/CT in a patient with prostate cancer. An 81-year-old man with prostate cancer (pT4, N2, M0, G3) with biochemical recurrence diagnosed by increased serum PSA levels from $6.59 \mathrm{ng} / \mathrm{mL}$ to $17.34 \mathrm{ng} / \mathrm{mL}$ over a 3-month interval, was referred for restaging. Whole-body SPECT-MIP (a) shows multiple sites of focal abnormal tracer uptake above and below the diaphragm. Transaxial
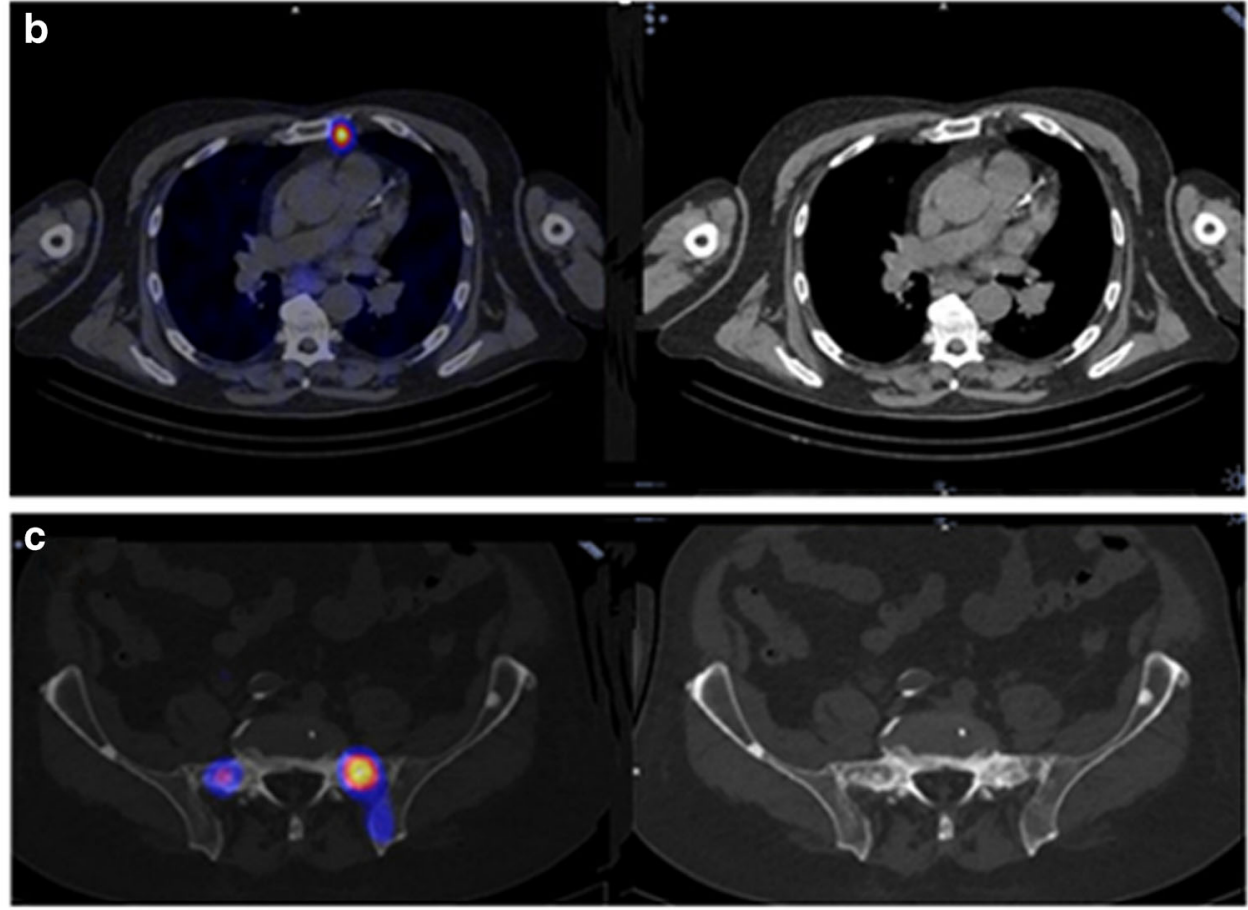

SPECT/CT and CT slices at the level of the upper thorax (b) demonstrate the presence of a left internal mammary chain lymph node metastasis. Transaxial SPECT/CT and CT slices at the level of the upper pelvis (c) show multiple, partially MIP-1404-avid osteoblastic lesions in the bone, consistent with functionally active and inactive skeletal metastases 


\section{Non-oncologic applications}

\section{Benign skeletal conditions}

${ }^{99 \mathrm{~m}} \mathrm{Tc}$-methylene diphosphonate (MDP) bone SPECT/CT plays a pivotal role in the assessment of musculoskeletal (MSK) diseases, including in patients with chronic pain or with inconclusive cross-sectional imaging results (Online Table 8), providing functional and localization information and identifying specific structural patterns. SPECT/CT has improved the diagnostic accuracy of BS in trauma and rheumatic diseases such as occult fractures, inflammatory arthritis, and spondyloarthropathies (Fig. 6) [94-96].

In patients with chronic low back pain (LBP), SPECT/CT has been used to guide therapy [97-99] and to assess complications following spine surgery [100-103]. In patients with recurrent pain following lumbar arthrodesis, SPECT/CT was highly sensitive and specific for exclusion of screw loosening [102]. In pelvic girdle pain and sacroiliac joint (SIJ) dysfunction, SPECT/CT diagnosed SIJ incompetence with sensitivity of $95 \%$, specificity of $99 \%$, PPV of $99 \%$, and NPV of $94 \%$ [104].

Diagnosis of hand and wrist pain by BS is challenging because of the complex regional anatomy. SPECT/CT can detect post-traumatic bone remodelling in occult fractures, often missed by other imaging tests [105-107]. SPECT/CT arthrography has been used for assessment of the scapholunate and lunotriquetral ligament or the triangular fibrocartilage complex [108]. In patients with nonspecific regional pain, SPECT/CT has shown a higher lesion detection rate than X-ray and planar BS [109] and higher specificity than MRI [110].

Detecting the source of pain following hip or knee replacement is not straightforward. X-ray is the initial test, often followed by BS to confirm or exclude septic or aseptic loosening. Increased tracer uptake identified on bone SPECT/CT in patients with total hip arthroplasty was shown to correlate significantly with symptoms $[111,112]$. While BS is hampered by nonspecific tracer uptake, the CT component of SPECT/CT can identify pain generators such as osteolysis, fracture, calcifications, and joint effusion. SPECT/CT demonstrated higher diagnostic accuracy in evaluating aseptic and septic loosening of hip and knee prostheses as compared with three-phase BS and SPECT [113-115].

SPECT/CT was used to evaluate bone viability after arthroplasty and was then compared with MRI. The two techniques were complementary in the differentiation between viable and nonviable tissue [116]. In patients following knee
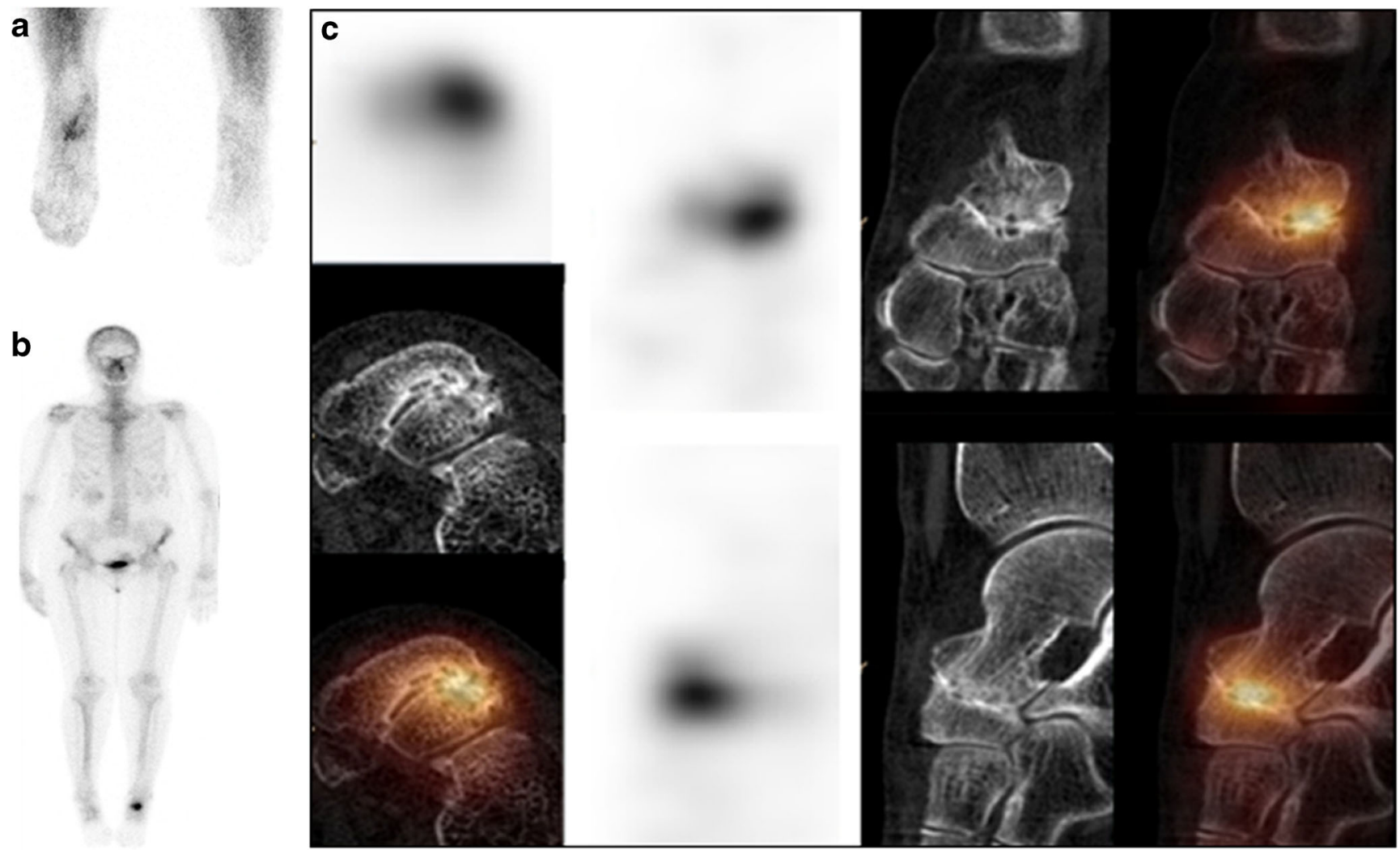

Fig. $6{ }^{99 \mathrm{~m}} \mathrm{Tc}-\mathrm{MDP}$ bone SPECT/CT in a patient with a painful left foot. A 70-year-old patient with persistent pain in the left foot was referred for bone scintigraphy (BS) for detection of the pain generator. Early planar scan of the feet (a) and delayed whole-body scan (b) show a focus of hyperaemia and intense tracer uptake in the posterior aspect of the left tarsal region, localized by SPECT/CT (c) to severe degenerative changes in the left talonavicular joint seen on the $\mathrm{CT}$ component 
replacement, SPECT/CT identified typical patterns in patellafemoral disorders, further improving the management of symptoms [117, 118]. After reconstruction of the anterior cruciate ligament, SPECT/CT identified bone remodelling, graft incorporation, or insufficiency $[119,120]$. SPECT/CT has also been useful in the follow-up after realignment treatment, osteotomies, and unloader devices or insoles.

Assessment of foot and ankle pain is challenged by regional anatomical complexity. SPECT/CT has been used in the diagnosis of fractures, infection, pseudoarthrosis, accessory sesamoid bones, tarsal coalition, and osteochondrosis dissecans [121]. SPECT/CT and MRI provided comparable diagnostic yield in painful lesions in the ankle and foot [122]. SPECT/CT of the foot was useful in the assessment of misaligned hindfoot [123] and in characterizing impingement syndromes and soft tissue (ST) pathology in this region [124, 125]. SPECT/CT of the skull was superior to BS for the diagnosis of active condylar hyperplasia [126].

\section{Infection}

While diagnosis of an infectious process is based on clinical and laboratory data, localization can be difficult. Infectionseeking tracers labelled with single-photon-emitting radionuclides include autologous leukocytes [white blood cells (WBC)] labelled with ${ }^{99 m}$ Tc-hexamethylpropyleneamine oxime (HMPAO) or ${ }^{111}$ In-oxine [127] and, to a lesser extent, radiolabelled antibiotics, antibodies [128, 129], and ${ }^{99 \mathrm{~m}} \mathrm{Tc}-$ ubiquicidin 29-41 [130]. ${ }^{67} \mathrm{Ga}$-citrate is still used in a few scenarios such as osteomyelitis (OM) of the spine or sternum [131-134]. SPECT/CT enables both early diagnosis of infection and precise localization. Although there has been a recent shift in infection imaging towards [ $\left.{ }^{18} \mathrm{~F}\right]$ FDG-PET/CT [135], SPECT/CT is a valid alternative.

SPECT/CT optimizes the diagnosis of clinically suspected MSK infections and localization of known processes. This is useful in cases when bone involvement has to be proven or excluded in the presence of soft tissue infection (STI) or for assessing the extent of OM in a complicated anatomical region such as in post-surgical alterations or close to implanted medical devices. Initial studies including mixed patient populations have reported that SPECT/CT with ${ }^{111} \mathrm{In}$ - or ${ }^{99 \mathrm{~m}} \mathrm{Tc}-\mathrm{la}-$ belled WBCs or ${ }^{67} \mathrm{Ga}$-citrate had high performance indices in one third of cases [128, 131, 136-138]. A total of 24 papers were retrieved from a literature search and retained for further analysis (Online Table 9).

$\mathrm{OM}$ has to be considered in any diabetic patient with chronic non-healing wounds, mainly in the feet. Studies reported that WBC scans confirmed the infection but SPECT/CT detected or excluded OM adjacent to STI in more than $50 \%$ of patients with diabetic foot [139-141], increasing specificity and PPV (Fig. 7) $[142,143]$. WBC-SPECT/CT was superior to $\left[{ }^{18} \mathrm{~F}\right] \mathrm{FDG}-\mathrm{PET} /$ CT [139] and similar to MRI [143] in the assessment of diabetic foot, with high sensitivity and NPV, but lower specificity and PPV at the end of antibiotic therapy [144, 145].

${ }^{67} \mathrm{Ga}$-citrate SPECT/CT demonstrated high diagnostic accuracy for spondylodiscitis, similar to MRI [132] but inferior to $\left[{ }^{18} \mathrm{~F}\right]$ FDG-PET/CT [134]. ${ }^{111}$ In-diethylenetriaminepentaaceticacid (DTPA)-biotin SPECT/CT was also used for localization of spinal infection and for tailoring of therapy [146].

Differentiating aseptic loosening of a prosthetic joint from infection defines the treatment strategy. The performance indices of ${ }^{99 \mathrm{~m}}$ Tc-WBC SPECT/CT reached $93 \%$ but were somewhat lower than for ${ }^{99 \mathrm{~m}} \mathrm{Tc}$-labelled antigranulocyte antibodies [129, 147].

SPECT/CT localized foci of infection to the jaw or other bones in the base of skull [148, 149] and diagnosed OM in cases with malignant otitis externa [150]. Dual-isotope ${ }^{99 \mathrm{~m}} \mathrm{Tc}$ MDP bone and ${ }^{111}$ In-oxine-WBC SPECT/CT provided high diagnostic confidence for evaluation of infected pelvic pressure sores [151].

STI has nonspecific clinical presentations and requires extensive diagnostic workup [131]. In this setting, SPECT/CT could be useful in vascular graft infection [131, 152-154], infectious endocarditis $[155,156]$, infection of cardiac implantable electronic devices [157, 158], and fever of unknown origin $[131,159,160]$. Eleven papers were retrieved from a literature search and retained for further analysis (Online Table 10).

\section{Parathyroid diseases}

${ }^{99 \mathrm{~m}}$ Tc-sestamibi (MIBI) SPECT/CT is used in the workup of patients with hyperparathyroidism (HPT). Variable acquisition protocols are used, including single-tracer dual-phase studies and subtraction imaging following ${ }^{99 \mathrm{~m}} \mathrm{Tc}$ pertechnetate or ${ }^{123}$ I-iodide administration. Timing of SPECT/CT early, late, or twice during imaging has been described [161-164].

The recent introduction of minimally invasive surgery for parathyroid adenoma (PTA) underscores the need for precise functional and topographic information provided by SPECT/ CT. The main current indication for parathyroid scintigraphy is preoperative localization of PTAs (Online Table 11, Fig. 8). The detectability of PTA by SPECT/CT ranged from 90 to $96 \%[165,166]$, particularly helpful for small lesions less than $10 \mathrm{~mm}$ in diameter $[54,166]$ or weighing less than $210 \mathrm{mg}$ [167]. ${ }^{99 \mathrm{~m}}$ Tc-MIBI SPECT/CT results were found to correlate with serum parathyroid hormone (PTH) and calcium levels $[162,168]$. SPECT/CT improved localization of PTAs in 8 $39 \%$ patients $[169,170]$, with a sensitivity range of $83-97 \%$, specificity of $89-96 \%$, PPV of $94-97 \%$, and NPV of $85 \%$ [161, 163, 167, 171-173]. SPECT/CT correctly localized both ectopic PTAs and residual lesions in patients with prior neck surgery [170]. ${ }^{99 \mathrm{~m}} \mathrm{Tc}-\mathrm{MIBI}$ SPECT/CT has led to a reduction of up to $50 \%$ in the duration of surgery $[166,172,173]$. 


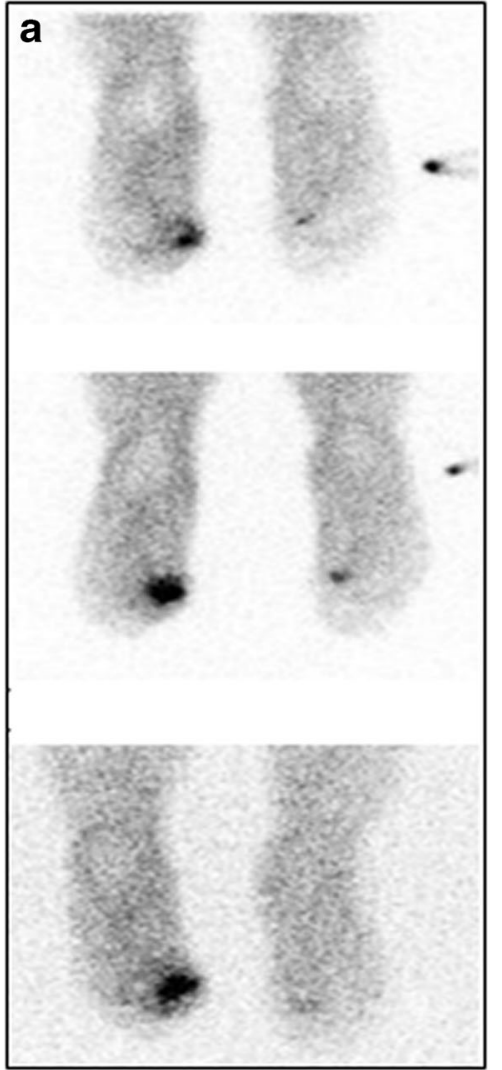

Fig. $7{ }^{99 \mathrm{~m}} \mathrm{Tc}-\mathrm{HMPAO}$-labelled leucocyte SPECT/CT in a patient with diabetic foot. A 43-year-old man with diabetes mellitus and an infected wound in the medial aspect of the left forefoot was referred for ${ }^{99 m} \mathrm{Tc}-$ HMPAO-leucocyte scintigraphy for suspected osteomyelitis. Planar scans (a) performed at $1 \mathrm{~h}$ (top), $4 \mathrm{~h}$ (center), and $24 \mathrm{~h}$ (bottom) after tracer injection show a focal area of uptake at the base of the first left digit,

Positive SPECT/CT is a good criterion for defining patient eligibility for surgery [174] and for surgical procedure planning, particularly in the presence of thyroid disease such as multinodular goitre [172]. ${ }^{99 \mathrm{~m}} \mathrm{Tc}-\mathrm{MIBI}$ SPECT/CT localization of a PTA was shown to be superior to both SPECT and ultrasound (US) [54, 165, 167, 171, 173] but not to multiphase 4D CT, which added information, mainly in non- ${ }^{99 \mathrm{~m}} \mathrm{Tc}-\mathrm{MIBI}-$ avid lesions $[175,176]$. In cases resistant to medical treatment, patients with secondary HPT are referred for parathyroidectomy, and preoperative ${ }^{99 \mathrm{~m}}$ Tc-MIBI SPECT/CT improved surgical outcome [177-179]. A total of 23 papers retrieved through a literature search were retained for further analysis.

\section{Lung disorders}

Ventilation and perfusion (V/Q) imaging is routinely used in the workup of patients with suspected pulmonary emboli (PE) [180]. In planar V/Q scans, distinction of anatomical segments is challenging, and it is difficult to determine the extent of embolic involvement [181-183].

CT pulmonary angiography (CTPA) has gradually replaced V/Q scans for PE, being widely available and having high increasing in intensity in its superior aspect. SPECT/CT (b) locates this uptake to fragments of the first left metatarsal bone showing areas of cortical erosion and sclerosis, as well as to the adjacent deep wound and surrounding edematous soft tissue, consistent with osteomyelitis in addition to the soft tissue infection

sensitivity and specificity. Nevertheless, CTPA is limited by technical artefacts, contrast allergy, or poor renal function $[184,185]$. V/Q SPECT has improved sensitivity over planar scintigraphy, but has lower specificity than CTPA [185-191]. V/Q SPECT/CT is typically performed with low-dose CT for purposes of anatomical localization and attenuation correction (AC) [192]. The addition of CT increased specificity (Fig. 9), comparable to CTPA, and characterized abnormalities seen on SPECT in the context of lung comorbidities $[189,193]$. In a comparison of V/Q SPECT, SPECT/CT, perfusion-only SPECT/CT, and CTPA for detection of PE, V/Q SPECT/CT achieved sensitivity and specificity of $100 \%[189,192]$.

$\mathrm{V} / \mathrm{Q}$ SPECT/CT has also been preliminarily described in nonPE applications including preoperative quantification of lung function, defining radiotherapy fields, and assessing regional changes in asthma, emphysema, or interstitial lung disease [192, 194-207].

\section{Cardiology}

Coronary artery disease (CAD) is the number one cause of cardiovascular morbidity and mortality. Current guidelines 
Fig. $8{ }^{99 m}$ Tc-Sestamibi SPECT/ CT for localization of parathyroid adenoma (PTA). A 57-year-old woman with laboratory evidence of primary hyperparathyroidism was referred for localization of PTA. Planar scintigraphy (a) shows an early area of increased focal uptake at the upper pole of the right thyroid lobe (left), with washout of the tracer from adjacent thyroid tissue on late images (right). SPECT/CT (b) performed $1 \mathrm{~h}$ after tracer injection localizes this focal uptake to a $16-\mathrm{mm}$ nodule behind the thyroid gland, consistent with a PTA
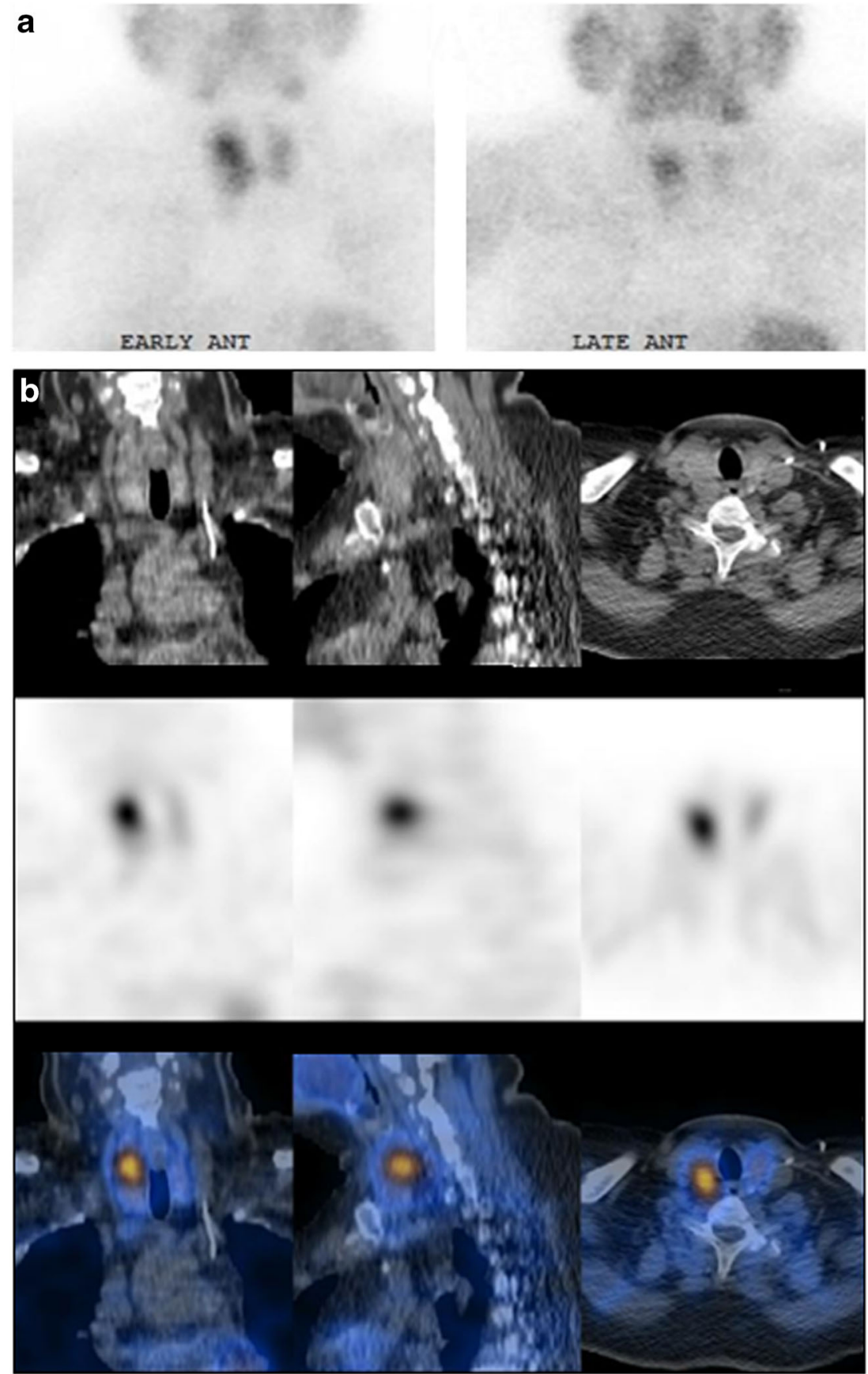

recommend that patients with low pretest probability for stable CAD undergo cardiac computed tomography angiography (CCTA), which has a high NPV, while patients with high pretest probability should be referred for invasive coronary angiography (ICA). The intermediate-risk group, comprising the majority patients, needs further assessment to define the haemodynamic significance and quantify ischaemia in addition to assessing the degree of stenosis.

Myocardial perfusion imaging (MPI) SPECT using ${ }^{99 \mathrm{~m}} \mathrm{Tc}-\mathrm{la}-$ belled tracers or ${ }^{201} \mathrm{Tl}$-chloride has been validated for diagnosis, risk stratification, and prognosis of CAD [208]. AC algorithms utilizing $\mathrm{CT}$ and iterative image reconstruction techniques have improved the image quality and diagnostic accuracy of SPECT (Fig. 10) [209]. MPI-SPECT with vs. without AC show sensitivity of $89 \%$ vs. $87 \%$ and specificity of $81 \%$ vs. $73 \%$, respectively [210]. SPECT/CT used for AC improved diagnostic confidence in the interpretation of stress-only MPI studies, thus reducing patient radiation exposure following the implementation of this protocol [211].

The CT component of SPECT/CT can be also used for coronary artery calcium score (CAC) measurements without significantly increasing the radiation exposure to the patient. SPECT/ 
Fig. 9 Lung SPECT/CT, perfusion study in suspected pulmonary embolism (PE). A 60year-old patient with clinical suspicion of pulmonary embolism was referred for pulmonary ventilation/perfusion scintigraphy. Planar scintigraphy selected posterior and posterior oblique views) shows normal ventilation (a), in the presence of multiple segmental and subsegmental perfusion defects in both lungs (b). SPECT/CT shows no corresponding abnormal parenchymal changes on the CT component of the study (c). The patient was diagnosed with a bilateral pulmonary embolism a
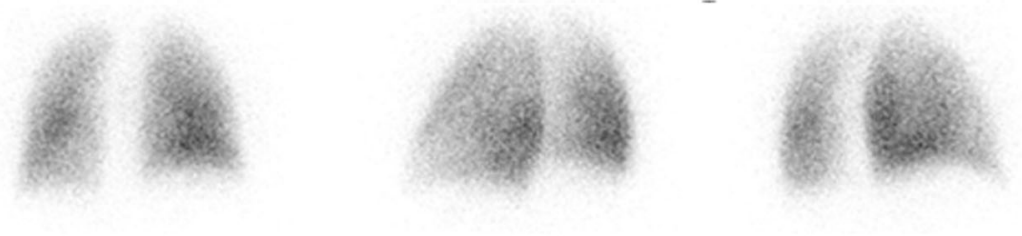

b
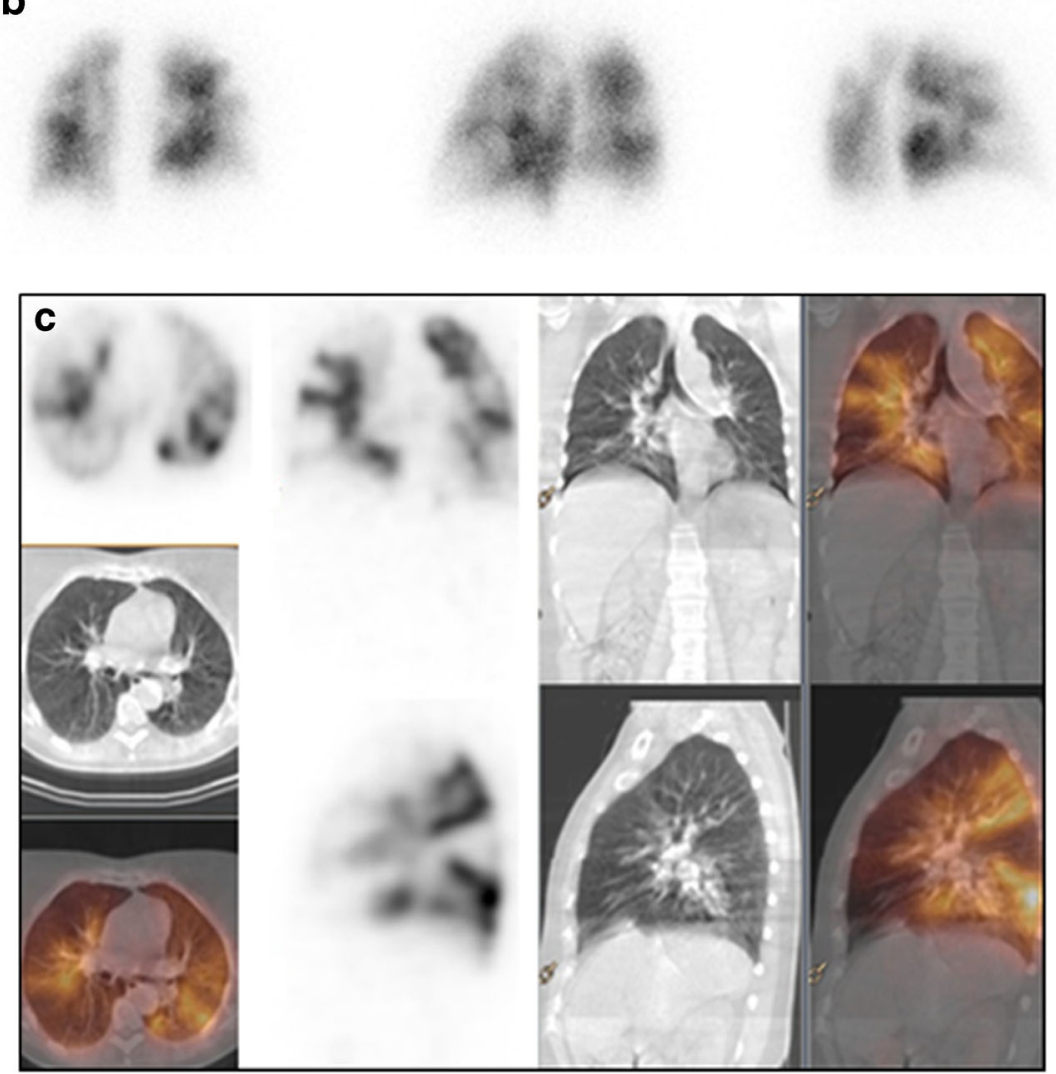

CT calcium scanning is becoming a routine part of MPI, with superior diagnostic and prognostic value $[212,213]$.

CCTA has high diagnostic accuracy for stenosis in native coronary arteries [214-219]. SPECT/CT systems equipped with components that enable sufficient resolution to perform CCTA are now available. SPECT/CCTA led to similar patient management when compared to ICA [220].

When combining MPI with CT, the patient is exposed to additional radiation varying from 0.5 to $1.0 \mathrm{mSv}$ for CT-AC. Absorbed doses for CAC and CCTA depend on the device and protocol used, estimated to be below $1 \mathrm{mSv}$ for CAC measurements and between 2 and $5 \mathrm{mSv}$ for CCTA, with latestgeneration CT scanners even below $1 \mathrm{mSv}$ [221, 222]. A total of 18 papers on cardiac SPECT/CT for AC, CAC measurements, or in combination with CCTA were retrieved by a literature search and retained for further analysis (Online Table 12).

\section{Neurology}

SPECT imaging of brain perfusion is performed in cases of dementia and epilepsy using ${ }^{99 \mathrm{~m}}$ Tc-HMPAO or ${ }^{99 \mathrm{~m}}$ Tc-ethyl cysteinate dimer (ECD). The addition of CT to SPECT has not led to a breakthrough in this setting, in part because CT is not the procedure of choice for brain imaging, with MRI being the better tool. In the majority of cases, the diagnostic gain with SPECT/CT is only negligible [223-233]. Nonetheless, when comparison to age-matched healthy controls is required, such as the examination of the dopamine transporters with ${ }^{123}$ I-FP CIT in cases of parkinsonism (Fig. 11), CT information helps to obtain a more robust spatial normalization of SPECT data [232-234]. The use of SPECT/CT in brain tumours with tracers such as ${ }^{99 \mathrm{~m}}$ Tc-MIBI and ${ }^{99 \mathrm{~m}}$ Tc-tetrofosmin (Myoview ${ }^{\circledR}$ ) or ${ }^{99 \mathrm{~m}}$ Tc-bis-methionine-DTPA (MDM) is limited and largely restricted to differentiation between recurrence and radiation necrosis [235].

\section{Gastrointestinal tract}

Active gastrointestinal (GI) bleeding is detected by contrast angiography or endoscopy if present at the time the study is performed. ${ }^{99 \mathrm{~m}}$ Tc-labelled red blood cell (RBC) scintigraphy is a highly sensitive, non-invasive tool to detect intermittent 

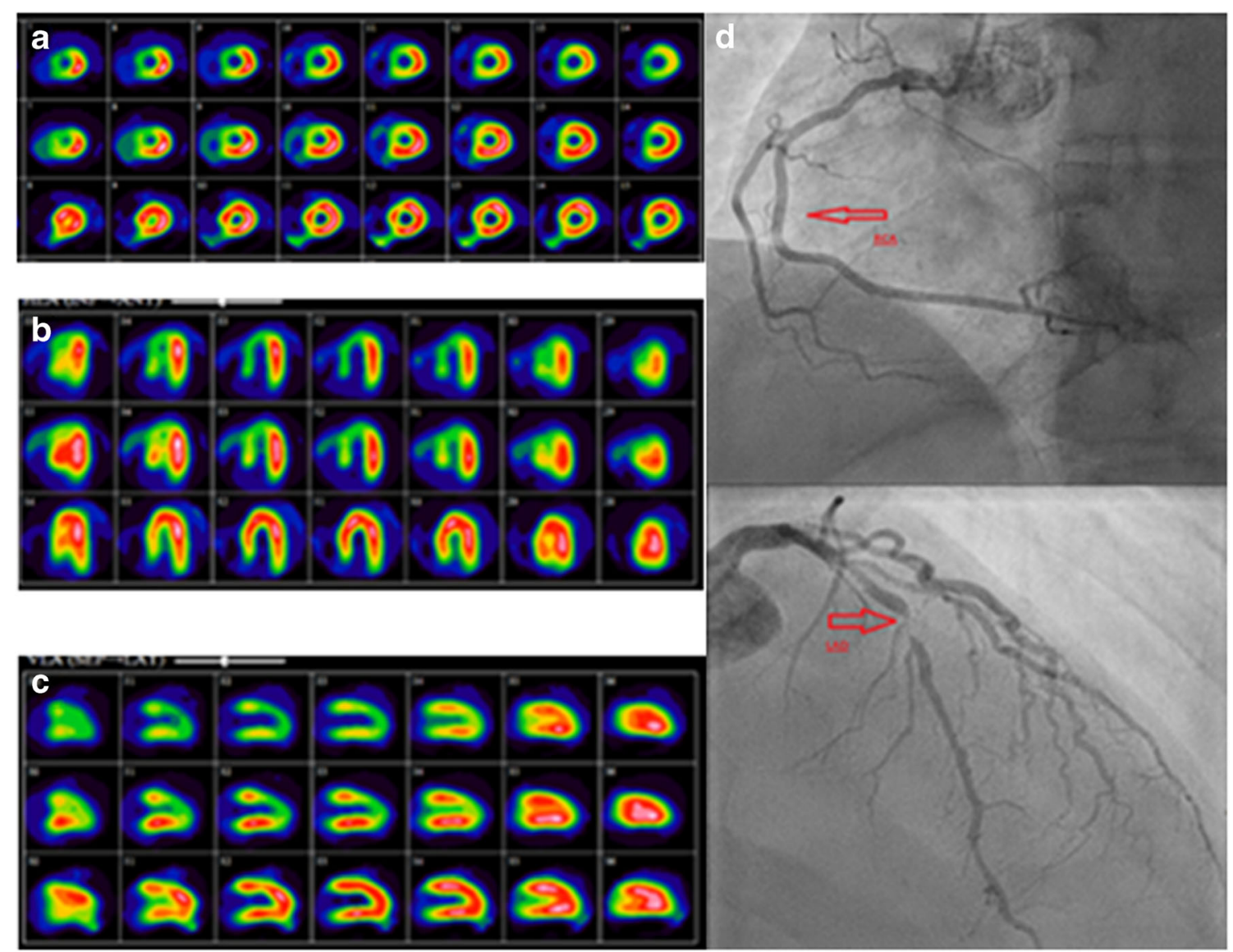

Fig. $10{ }^{99 \mathrm{~m}}$ Tc-tetrofosmin cardiac SPECT/CT for attenuation correction. A patient presenting with chest pain and with family history of CAD was referred for a myocardial perfusion SPECT/CT using a single-tracer oneday stress-rest protocol with ${ }^{99 \mathrm{~m}} \mathrm{Tc}$-tetrofosmin. CT AC was performed for the stress study. MPI-SPECT short (a), horizontal (b), and vertical (c) long axis show moderate reduction in tracer uptake in the anteroseptal wall sparing the anterobasal segment, and in the inferior wall and the apex on the non-corrected images at stress (first row), normalizing at rest (third row), suggests the presence of moderate ischemia in the territories of the

bleeding. Positive studies identify patients who need immediate treatment if the site of bleeding is localized [236]. SPECT/ CT was found to improve bleeding source localization in over $30 \%$ of cases [237] and, increased sensitivity from $89 \%$ to 93\% compared to planar scans, with improved positional accuracy of the bleeding site in $92 \%$ vs. $74 \%$ of patients [238]. Timing of ${ }^{99 \mathrm{~m}} \mathrm{Tc}-\mathrm{RBC}$ SPECT/CT acquisition needs further evaluation. There is also concern that during the relatively long SPECT/CT acquisition, patient motion or bowel artefacts can affect correct localization of the bleeding site $[239,240]$.

\section{Paediatrics applications}

The use of SPECT/CT in children and adolescent patients can reduce the number of equivocal studies and spare further diagnostic workup [241]. However, the practice of CT in left anterior descending (LAD) and right coronary (RCA) arteries. AC stress images (second row) confirm the presence of decreased uptake in the territory of the LAD only (the anteroseptal wall and apex), while correcting the attenuation artefact caused by the diaphragm in the inferior wall. The findings are consistent with a large area of moderate ischemia in the territory supplied by the LAD. Coronary angiography (c) demonstrates normal RCA (top, arrow) and a critical lesion in the proximal LAD (bottom, arrow)

children requires expertise to balance the best diagnostic yield with minimum radiation burden $[242,243]$. The use and extent of the CT field should be selected based on clinical question, scintigraphic findings, and previous imaging modalities.

Bone SPECT/CT in children is performed mainly in benign conditions [244, 245]. Although MRI has taken over the main imaging role, in centers with no easy access to it, BS with SPECT/CT is a helpful option [246]. In orthopaedics, sports, and traumatic injuries in children, SPECT/CT can identify the pain generator at the cortical bone level, where MRI is less sensitive. In adolescent back pain, including spondylolysis, SPECT/CT is of value when X-rays and MRI have failed to identify the source of pain (Fig. 12) [247]. BS with targeted SPECT/CT plays a role in children with suspected bone and joint infections but without localizing symptoms, such as OM, spondylodiscitis, and septic arthritis [244, 245, 248]. Additional clinical indications for SPECT/CT in children 

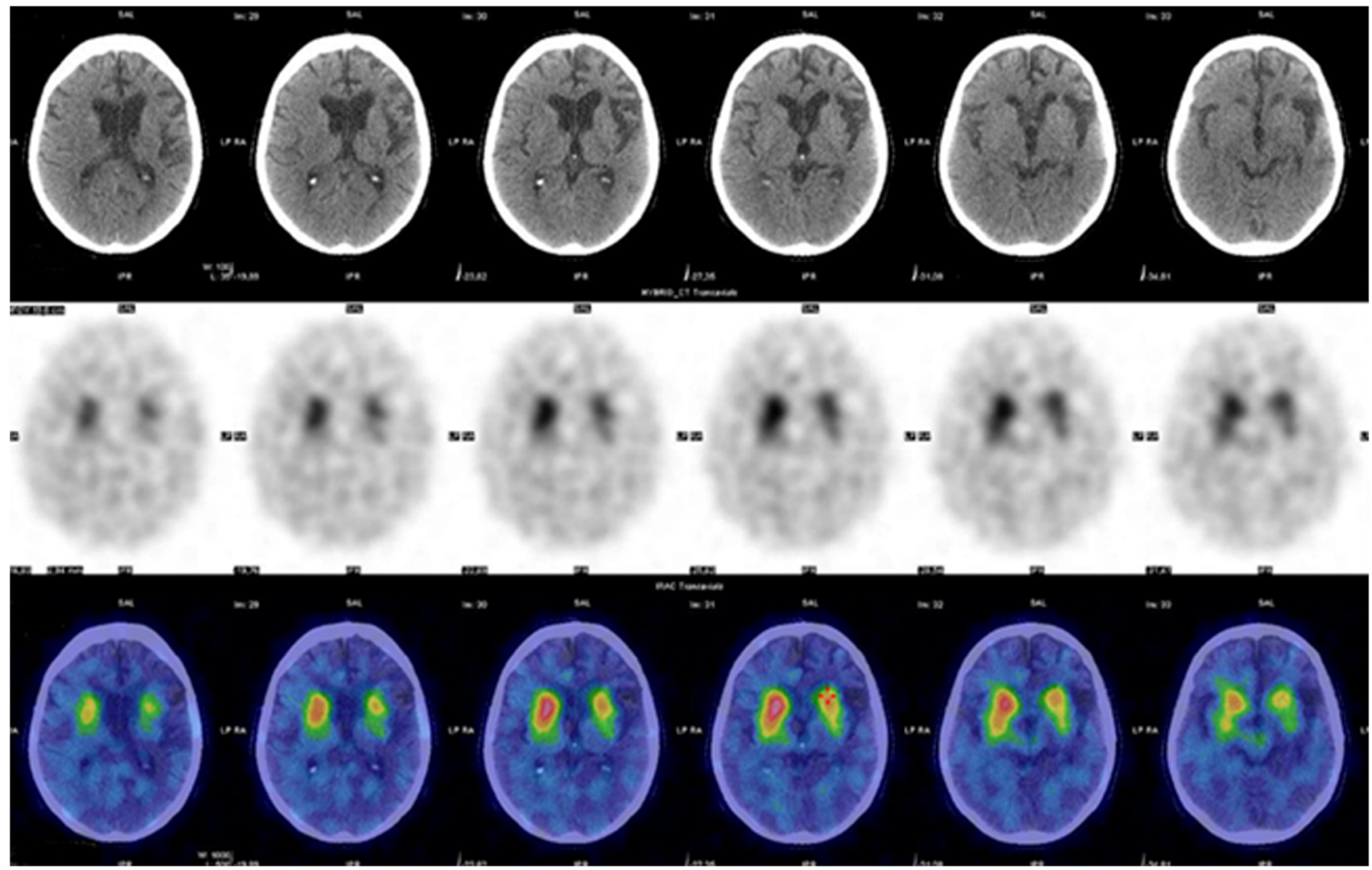

Fig. $11{ }^{123}$ I-FP-CIT SPECT/CT in a patient with parkinsonism. A 63year-old man with parkinsonian symptoms for the past 12 months, initially diagnosed as Parkinson's disease but with no appreciable response to L-DOPA treatment, was referred to brain scintigraphy. Transaxial SPECT and SPECT/CT (centre and bottom row) show reduced tracer uptake in the left putamen. CT (top row) demonstrates ipsilateral cortical atrophy. These combined findings suggest a diagnosis of corticobasal atrophy with associated parkinsonism, rather than typical Parkinson's disease. [Images provided courtesy of Dr. Duccio Volterrani, Regional Center of Nuclear Medicine, University of Pisa, Italy] include radiologically occult stress fractures and evaluation of congenital skeletal abnormalities of the spine or the extremities [249].

In paediatric solid tumours, SPECT/CT is used mainly with neuroblastic tumours and thyroid cancer. Neuroblastoma occurs in the adrenals and sympathetic ganglia. CeCT or MRI evaluate the size and position of the primary tumour in relationship to surrounding organs. ${ }^{123} \mathrm{I}$-mIBG SPECT/CT improves diagnostic accuracy (Fig. 13) and reduces the incidence of equivocal planar findings [250]. Sedation or general anaesthesia is often required for this lengthy examination in young children. Acquisition of a fully diagnostic ceCT as part of the SPECT/CT study is an option, in order to avoid an additional examination, thus providing a "one-stop shop" evaluation with a single exposure to anaesthesia $[250,251]$.

DTC, although uncommon, has a rising incidence in children who tend to have a more aggressive type as compared to adults [252]. ${ }^{123}$ I-iodide WBS with SPECT/CT is not recommended in low-risk disease but provided important information on residual thyroid tissue, nodal and distant metastases in patients with high risk DTC $[253,254]$.
Meckel diverticulum is the most frequent cause of lower GI haemorrhage in children. SPECT/CT improved diagnosis and localization of ectopic gastric mucosa, mainly in uncommon sites, and identified artefactual foci [242, 255]. Limited literature evidence indicates that SPECT/CT can potentially increase the diagnostic yield of ${ }^{99 \mathrm{~m}} \mathrm{Tc}-\mathrm{WBC}$ imaging in paediatric infections [256] and of MPI in assessing congenital heart disease, complementary to echocardiography [257].

\section{Incidental CT findings}

Because of the rapid increase in the use of diagnostic-quality SPECT/CT studies, incidentalomas, i.e. unexpected findings not related to the initial diagnostic inquiry, are often detected on the CT component. The reporting physicians should be aware of these incidental findings and their clinical significance. Incidentalomas have been categorized as major, moderate, or minor findings (Online Table 13). In the presence of major incidental findings, the referring clinician should be informed, and further investigations are in order to prevent 


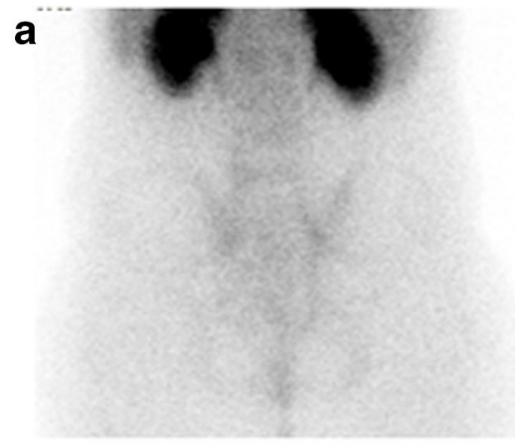

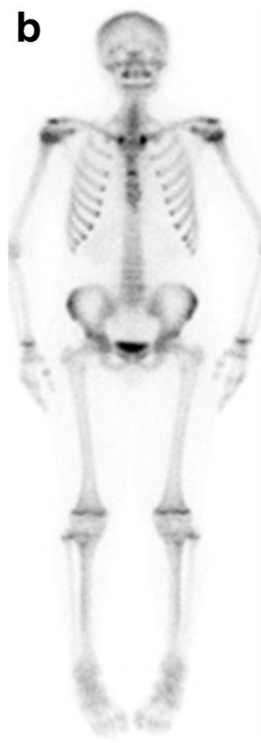

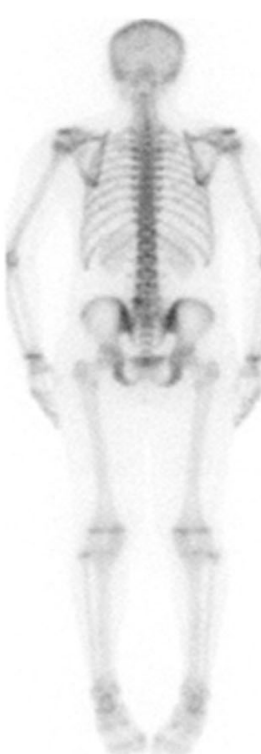

Fig. 12 Bone SPECT/CT diagnosis of spondylolysis in an adolescent patient. A14-year-old girl was referred for evaluation of persistent low back pain. Early planar scan of lumbar spine and pelvis (a) shows no hyperaemia. Delayed WB-BS, anterior and posterior views (b) show a

adverse health effects. Moderate findings usually require further investigation, but their clinical impact is unclear. Minor findings rarely require further investigation and are unlikely to have adverse health effects [258-265].

\section{Concluding remarks}

Within the domain of radionuclide-based diagnostic procedures, hybrid imaging has gained wide popularity, largely following the introduction of PET/CT into clinical routine. The metabolic or functional information provided by PET or SPECT is enhanced not only because of better AC, but also, and most importantly, due to the correlative assessment of altered tracer distribution with anatomical structures. This results in better performance indices for the diagnostic imaging procedure. Through hybrid imaging in general, and SPECT/ $\mathrm{CT}$ in particular, the nuclear medicine expert brings an important contribution to better healthcare by tailoring clinical interventions to the individual patient's needs. The authors are focus of abnormal ${ }^{99 \mathrm{~m}} \mathrm{Tc}-\mathrm{MDP}$ uptake in left aspect of L5 vertebra, localized by SPECT/CT (c) to the left L-5 articular facet, consistent with spondylolysis

aware that "competitive" PET/CT methods exist for many of the indications discussed in the present review. When available, these methods are mentioned (see also online Tables). However, an extensive review of these other modalities was not the focus of this article.

By analysing the most relevant of over 400 papers published so far on the topic of clinical SPECT/CT, the current review provides an update on the established evidence. It demonstrates the definite advantages of SPECT/CT over planar and/or stand-alone SPECT in a variety of diseases. For most of the applications described above, SPECT/CT is already fully integrated into the routine clinical decisionmaking process. The information gathered whilst performing this review also points to areas where the application of integrated SPECT/CT imaging has not yet been proven to have definite advantages. The lack of large-scale studies and clear evidence-based proof do not permit the authors at present to translate the implementation of SPECT/CT into significant clinical impact for management. The potential of SPECT/CT imaging for lesion characterization will increase, especially 

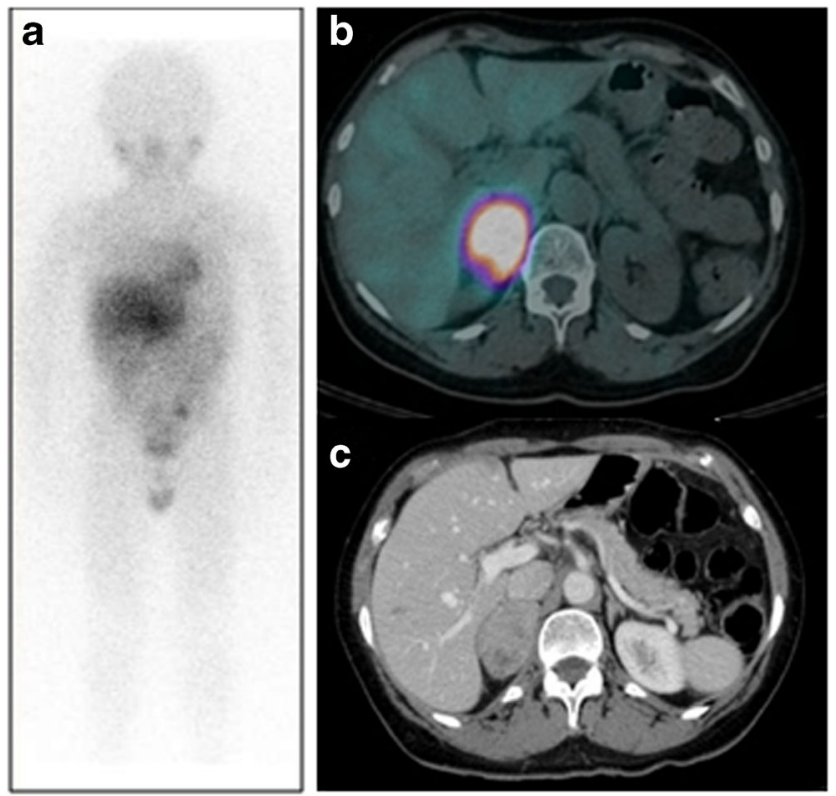

Fig. $13{ }^{123} \mathrm{I}$-mIBG SPECT/CT in neuroblastoma. A 6-year-old child with newly diagnosed neuroblastoma was referred for staging. Planar WB scan (a) shows an area of increased uptake in the right upper abdomen, partially overlapping the liver of unclear location and clinical significance. SPECT/CT (b) localizes this abnormal tracer uptake to the primary lesion in a large mass in the right adrenal seen on CT $(\mathbf{C})$

following the use of diagnostic ceCT. Recent technological advances will also enhance the role to be played by quantitative SPECT/CT for dosimetry estimates in theragnostics, a topic that deserves a separate, dedicate assessment of current knowledge and contributions. It is therefore expected that the literature and conclusions summarized above will undergo continuing significant changes. The present data and trends for the near future reinforce, with respect to SPECT/CT, the axiom stated by the Greek philosopher Aristotle (384-322 BC) that "the whole is greater than the sum of its parts".

Acknowledgements The authors are grateful to the International Atomic Energy Agency (IAEA) for scientific and logistic support.

\section{Compliance with ethical standards}

Conflict of interest Ora Israel: consultant for GE Healthcare

Gopinath Gnanasegaran: symposia attendance support, Norgine Radiopharmaceuticals

Torsten Kuwert: speaker honoraria, Siemens Healthineers and Sanofi; institutional research grant, Siemens Healthineers; institutional material support, Progenics

Christian la Fougère: consultant, speaker honoraria, research grant, GE Healthcare; research grants, Siemens Healthineers; consultant for Bayer

Samia Massalha: Tucker Research Fellowship award, University of Ottawa Heart Institute

Olivier Pellet, Lorenzo Biassoni, Diego De Palma, Enrique EstradaLobato, Giuliano Mariani, Diana Paez D and Francesco Giammarile have no conflicts of interest to declare
Open Access This article is distributed under the terms of the Creative Commons Attribution 4.0 International License (http:// creativecommons.org/licenses/by/4.0/), which permits unrestricted use, distribution, and reproduction in any medium, provided you give appropriate credit to the original author(s) and the source, provide a link to the Creative Commons license, and indicate if changes were made.

\section{References}

1. Alavi A, Basu S. Planar and SPECT imaging in the era of PET and PET-CT: can it survive the test of time? Eur J Nucl Med Mol Imaging. 2008;35:1554.

2. Mariani G, Strauss HW. Positron emission and single-photon emission imaging: synergy rather than competition. Eur J Nucl Med Mol Imaging. 2011;38:1189-90.

3. Bischof Delaloye A, Carrió I, Cuocolo A, Knapp W, Gourtsoyiannis N, McCall I, et al. White paper of the European Association of Nuclear Medicine (EANM) and the European Society of Radiology (ESR) on multimodality imaging. Eur J Nucl Med Mol Imaging. 2007;34:1147-51.

4. Kashyap R, Dondi M, Paez D, Mariani G, editors. Hybrid imaging worldwide - challenges and opportunities for the developing world: a report of a technical meeting organized by IAEA. Semin Nucl Med. 2013;43:208-23.

5. Mariani G, Bruselli L, Kuwert T, Kim EE, Flotats A, Israel O, et al. A review on the clinical uses of SPECT/CT. Eur J Nucl Med Mol Imaging. 2010;37:1959-85.

6. Even-Sapir E, Lerman H, Lievshitz G, Khafif A, Fliss DM, Schwartz A, et al. Lymphoscintigraphy for sentinel node mapping using a hybrid SPECT/CT system. J Nucl Med. 2003;44:1413-20.

7. Giammarile F, Schilling C, Gnanasegaran G, Bal C, Oyen WJ, Rubello D, et al. The EANM practical guidelines for sentinel lymph node localisation in oral cavity squamous cell carcinoma. Eur J Nucl Med Mol Imaging. 2019;46:623-37.

8. Broglie MA, Haerle SK, Huber GF, Haile SR, Stoeckli SJ. Occult metastases detected by sentinel node biopsy in patients with early oral and oropharyngeal squamous cell carcinomas: impact on survival. Head Neck. 2013;35:660-6.

9. Den Toom IJ, van Schie A, van Weert S, Karagozoglu KH, Bloemena E, Hoekstra OS, et al. The added value of SPECT-CT for the identification of sentinel lymph nodes in early stage oral cancer. Eur J Nucl Med Mol Imaging. 2017;44:998-1004.

10. Díaz-Feijoo B, Pérez-Benavente MA, Cabrera-Diaz S, GilMoreno A, Roca I, Franco-Camps S, et al. Change in clinical management of sentinel lymph node location in early stage cervical cancer: the role of SPECT/CT. Gynecol Oncol. 2011;120:3537.

11. Klapdor R, Mücke J, Schneider M, Länger F, Gratz K-F, Hillemanns $\mathrm{P}$, et al. Value and advantages of preoperative sentinel lymph node imaging with SPECT/CT in cervical cancer. Int J Gynecol Cancer. 2014;24:295-302.

12. Collarino A, Donswijk ML, van Driel WJ, Stokkel MP, Olmos RAV. The use of SPECT/CT for anatomical mapping of lymphatic drainage in vulvar cancer: possible implications for the extent of inguinal lymph node dissection. Eur J Nucl Med Mol Imaging. 2015;42:2064-71.

13. Klapdor R, Länger F, Gratz K, Hillemanns P, Hertel H. SPECT/ CT for SLN dissection in vulvar cancer: Improved SLN detection and dissection by preoperative three-dimensional anatomical localisation. Gynecol Oncol. 2015;138:590-6.

14. Naaman Y, Pinkas L, Roitman S, Ikher S, Oustinov N, Vaisbuch E, et al. The added value of SPECT/CT in sentinel lymph nodes 
mapping for endometrial carcinoma. Ann Surg Oncol. 2016;23: $450-5$.

15. Naumann CM, Colberg C, Jüptner M, Marx M, Zhao Y, Jiang P, et al. Evaluation of the diagnostic value of preoperative sentinel lymph node (SLN) imaging in penile carcinoma patients without palpable inguinal lymph nodes via single photon emission computed tomography/computed tomography (SPECT/CT) as compared to planar scintigraphy. Urol Oncol. 2018;36:92.e17-24.

16. Haugen BR, Alexander EK, Bible KC, Doherty GM, Mandel SJ, Nikiforov YE, et al. 2015 American Thyroid Association Management Guidelines for Adult Patients with Thyroid Nodules and Differentiated Thyroid Cancer: The American Thyroid Association Guidelines Task Force on Thyroid Nodules and Differentiated Thyroid Cancer. Thyroid. 2016;26:1-133.

17. Agrawal K, Bhattacharya A, Mittal BR. Role of single photon emission computed tomography/computed tomography in diagnostic iodine-131 scintigraphy before initial radioiodine ablation in differentiated thyroid cancer. Indian J Nucl Med. 2015;30:2216.

18. Aide N, Heutte N, Rame J-P, Rousseau E, Loiseau C, Henry-Amar $\mathrm{M}$, et al. Clinical relevance of single-photon emission computed tomography/computed tomography of the neck and thorax in postablation 131I scintigraphy for thyroid cancer. J Clin Endocrinol Metab. 2009;94:2075-84.

19. Avram AM, Esfandiari NH, Wong KK. Preablation 131-I scans with SPECT/CT contribute to thyroid cancer risk stratification and 131-I therapy planning. J Clin Endocrinol Metab. 2015;100:1895902.

20. Avram AM, Fig LM, Frey KA, Gross MD, Wong KK. Preablation 131-I scans with SPECT/CT in postoperative thyroid cancer patients: what is the impact on staging? J Clin Endocrinol Metab. 2013;98:1163-71.

21. Chen L, Luo Q, Shen Y, Yu Y, Yuan Z, Lu H, et al. Incremental value of 131I SPECT/CT in the management of patients with differentiated thyroid carcinoma. J Nucl Med. 2008;49:1952-7.

22. Ciappuccini R, Heutte N, Trzepla G, Rame J-P, Vaur D, Aide N, et al. Postablation 131I scintigraphy with neck and thorax SPECT-CT and stimulated serum thyroglobulin level predict the outcome of patients with differentiated thyroid cancer. Eur J Endocrinol. 2011;164:961-9.

23. Frangos S, Iakovou IP, Marlowe RJ, Eftychiou N, Patsali L, Vanezi A, et al. Acknowledging gray areas: 2015 vs. 2009 American Thyroid Association differentiated thyroid cancer guidelines on ablating putatively low-intermediate-risk patients. Eur J Nucl Med Mol Imaging. 2017;44:185-9.

24. Gonzalez Carvalho JM, Görlich D, Schober O, Wenning C, Riemann B, Verburg FA, et al. Evaluation of 131 I scintigraphy and stimulated thyroglobulin levels in the follow up of patients with DTC: a retrospective analysis of 1420 patients. Eur J Nucl Med Mol Imaging. 2017;44:744-56.

25. Barwick T, Murray I, Megadmi H, Drake WM, Plowman PN, Akker SA, et al. Single photon emission computed tomography (SPECT)/computed tomography using Iodine-123 in patients with differentiated thyroid cancer: additional value over whole body planar imaging and SPECT. Eur J Endocrinol. 2010;162:1131-9.

26. Jeong SY, Lee SW, Kim HW, Song BI, Ahn BC, Lee J. Clinical applications of SPECT/CT after first I-131 ablation in patients with differentiated thyroid cancer. Clin Endocrinol. 2014;81: 445-51.

27. Kohlfuerst S, Igerc I, Lobnig M, Gallowitsch H, Gomez-Segovia I, Matschnig S, et al. Posttherapeutic 131 I SPECT-CT offers high diagnostic accuracy when the findings on conventional planar imaging are inconclusive and allows a tailored patient treatment regimen. Eur J Nucl Med Mol Imaging. 2009;36:886-93.

28. Lee M, Lee Y, Jeon T, Chang H, Kim B-W, Lee Y, et al. Frequent visualization of thyroglossal duct remnant on post-ablation 131I-
SPECT/CT and clinical implications. Clin Radiol. 2015;70:63843.

29. Maruoka Y, Abe K, Baba S, Isoda T, Sawamoto H, Tanabe Y, et al. Incremental diagnostic value of SPECT/CT with 131I scintigraphy after radioiodine therapy in patients with well-differentiated thyroid carcinoma. Radiology. 2012;265:902-9.

30. Mínguez P, Flux G, Genollá J, Delgado A, Rodeño E, Sjögreen Gleisner K. Whole-remnant and maximum-voxel SPECT/CT dosimetry in 131I-NaI treatments of differentiated thyroid cancer. Med Phys. 2016;43:5279-87.

31. Mustafa M, Kuwert T, Weber K, Knesewitsch P, Negele T, Haug $\mathrm{A}$, et al. Regional lymph node involvement in $\mathrm{T} 1$ papillary thyroid carcinoma: a bicentric prospective SPECT/CT study. Eur J Nucl Med Mol Imaging. 2010;37:1462-6.

32. Oh J-R, Byun B-H, Hong S-P, Chong A, Kim J, Yoo S-W, et al. Comparison of 131 I whole-body imaging, 131 I SPECT/CT, and 18 F-FDG PET/CT in the detection of metastatic thyroid cancer. Eur J Nucl Med Mol Imaging. 2011;38:1459-68.

33. Ruf J, Lehmkuhl L, Bertram H, Sandrock D, Amthauer H, Humplik B, et al. Impact of SPECT and integrated low-dose CT after radioiodine therapy on the management of patients with thyroid carcinoma. Nucl Med Commun. 2004;25:1177-82.

34. Ruhlmann M, Jentzen W, Ruhlmann V, Pettinato C, Rossi G, Binse I, et al. High level of agreement between pretherapeutic 124I PET and intratherapeutic 131I imaging in detecting iodinepositive thyroid cancer metastases. J Nucl Med. 2016;57:133942.

35. Schmidt D, Linke R, Uder M, Kuwert T. Five months' follow-up of patients with and without iodine-positive lymph node metastases of thyroid carcinoma as disclosed by $131 \mathrm{I}-\mathrm{SPECT} / \mathrm{CT}$ at the first radioablation. Eur J Nucl Med Mol Imaging. 2010;37:699_ 705.

36. Schmidt D, Szikszai A, Linke R, Bautz W, Kuwert T. Impact of 131I SPECT/spiral CT on nodal staging of differentiated thyroid carcinoma at the first radioablation. J Nucl Med. 2009;50:18-23.

37. Shapiro B, Rufini V, Jarwan A, Geatti O, Kearfott KJ, Fig LM, et al. Artifacts, anatomical and physiological variants, and unrelated diseases that might cause false-positive whole-body 131-I scans in patients with thyroid cancer. Semin Nucl Med. 2000;30: 115-32.

38. Shen C-T, Wei W-J, Qiu Z-L, Song H-J, Luo Q-Y. Value of posttherapeutic 131 I scintigraphy in stimulated serum thyroglobulinnegative patients with metastatic differentiated thyroid carcinoma. Endocrine. 2016;51:283-90.

39. Spanu A, Solinas ME, Chessa F, Sanna D, Nuvoli S, Madeddu G. 131I SPECT/CT in the follow-6up of differentiated thyroid carcinoma: incremental value versus planar imaging. J Nucl Med. 2009;50:184-90.

40. Grewal RK, Michael Tuttle R, Fox J, Borkar S, Chou JF, Gonen $\mathrm{M}$, et al. The effect of posttherapy 131I SPECT/CT on risk classification and management of patients with differentiated thyroid cancer. J Nucl Med. 2010;51:1361-6.

41. Sriprapaporn J, Sethanandha C, Yingsa-nga T, Komoltri C, Thongpraparn T, Harnnanthawiwai C. Utility of adding SPECT/ CT imaging to post-therapeutic radioiodine whole-body scan in patients with differentiated thyroid cancer. J Med Assoc Thail. 2015;98:596-605.

42. Szujo S, Sira L, Bajnok L, Bodis B, Gyory F, Nemes O, et al. The impact of post-radioiodine therapy SPECT/CT on early risk stratification in differentiated thyroid cancer; a bi-institutional study. Oncotarget. 2017;8:79825.

43. Tharp K, Israel O, Hausmann J, Bettman L, Martin W, Daitzchman M, et al. Impact of 131I-SPECT/CT images obtained with an integrated system in the follow-up of patients with thyroid carcinoma. Eur J Nucl Med Mol Imaging. 2004;31:1435-42. 
44. Van Nostrand D. Selected controversies of radioiodine imaging and therapy in differentiated thyroid cancer. Endocrinol Metab Clin N Am. 2017;46:783-93.

45. Verburg FA, Aktolun C, Chiti A, Frangos S, Giovanella L, Hoffmann M, et al. Why the European Association of Nuclear Medicine has declined to endorse the 2015 American Thyroid Association management guidelines for adult patients with thyroid nodules and differentiated thyroid cancer. Eur J Nucl Med Mol Imaging. 2016;43:1001-5.

46. Wakabayashi H, Nakajima K, Fukuoka M, Inaki A, Nakamura A, Kayano D, et al. Double-phase 131 I whole body scan and 131 I SPECT-CT images in patients with differentiated thyroid cancer: their effectiveness for accurate identification. Ann Nucl Med. 2011;25:609-15.

47. Wang H, Fu H-L, Li J-N, Zou R-J, Gu Z-H, Wu J-C. The role of single-photon emission computed tomography/computed tomography for precise localization of metastases in patients with differentiated thyroid cancer. Clin Imaging. 2009;33:49-54.

48. Wong KK, Sisson JC, Koral KF, Frey KA, Avram AM. Staging of differentiated thyroid carcinoma using diagnostic 131I SPECT/ CT. AJR Amer J Roentgen. 2010;195:730-6.

49. Wong KK, Cahill JM, Frey KA, Avram AM. Incremental value of 111-In pentetreotide SPECT/CT fusion imaging of neuroendocrine tumors. Acad Radiol. 2010;17:291-7.

50. Zeuren R, Biagini A, Grewal RK, Randolph GW, Kamani D, Sabra MM, et al. RAI thyroid bed uptake after total thyroidectomy: A novel SPECT-CT anatomic classification system. Laryngoscope. 2015;125:2417-24.

51. Zilioli V, Peli A, Panarotto MB, Magri G, Alkraisheh A, Wiefels $\mathrm{C}$, et al. Differentiated thyroid carcinoma: Incremental diagnostic value of $131 \mathrm{I}$ SPECT/CT over planar whole body scan after radioiodine therapy. Endocrine. 2017;56:551-9.

52. Ait Boudaoud A, Verges B, Petit JM, Tatulashvili S, Cochet A, Humbert O. Uptake in the pancreatic uncinate process on the 111In-octreotide scintigraphy: How to distinguish physiological from pathological uptake? Nucl Med Commun. 2017;38:737-43.

53. Apostolova I, Riethdorf S, Buchert R, Derlin T, Brenner W, Mester J, et al. SPECT/CT stabilizes the interpretation of somatostatin receptor scintigraphy findings: a retrospective analysis of inter-rater agreement. Ann Nucl Med. 2010;24:477-83.

54. Bural GG, Muthukrishnan A, Oborski MJ, Mountz JM. Improved benefit of SPECT/CT compared to SPECT alone for the accurate localization of endocrine and neuroendocrine tumors. Mol Imag Radionucl Therapy. 2012;21:91-6.

55. Castaldi P, Rufini V, Treglia G, Bruno I, Perotti G, Stifano G, et al. Impact of 111 In-DTPA-octreotide SPECT/CT fusion images in the management of neuroendocrine tumours. Radiol Med. 2008;113:1056-67.

56. Chang CA, Pattison DA, Tothill RW, Kong G, Akhurst TJ, Hicks RJ, et al. 68 Ga-DOTATATE and 18 F-FDG PET/CT in paraganglioma and pheochromocytoma: utility, patterns and heterogeneity. Cancer Imaging. 2016;16:22-8.

57. Chiaravalloti A, Spanu A, Danieli R, Dore F, Piras B, Falchi A, et al. 111In-Pentetreotide SPECT/CT in pulmonary carcinoid. Anticancer Res. 2015;35:4265-70.

58. Derlin T, Busch JD, Wisotzki C, Schoennagel BP, Bannas P, Papp $\mathrm{L}$, et al. Intraindividual comparison of 123I-mIBG SPECT/MRI, 123I-mIBG SPECT/CT, and MRI for the detection of adrenal pheochromocytoma in patients with elevated urine or plasma catecholamines. Clin Nucl Med. 2013;38:e1-6.

59. Camargo Etchebehere ECS, Oliveira Santos A, Gumz B, Vicente A, Hoff PG, Corradi G, et al. 68Ga-DOTATATE PET/CT, 99mTcHYNIC-octreotide SPECT/CT, and whole-body MR imaging in detection of neuroendocrine tumors: a prospective trial. J Nucl Med. 2014;55:1598-604.
60. Fukuoka M, Taki J, Mochizuki T, Kinuya S. Comparison of diagnostic value of I-123 MIBG and high-dose I-131 MIBG scintigraphy including incremental value of SPECT/CT over planar image in patients with malignant pheochromocytoma/paraganglioma and neuroblastoma. Clin Nucl Med. 2011;36:1-7.

61. Hillel P, Van Beek E, Taylor C, Lorenz E, Bax N, Prakash V, et al. The clinical impact of a combined gamma camera/CT imaging system on somatostatin receptor imaging of neuroendocrine tumours. Clin Radiol. 2006;61:579-87.

62. Krausz Y, Keidar Z, Kogan I, Even-Sapir E, Bar-Shalom R, Engel A, et al. SPECT/CT hybrid imaging with 111 In-pentetreotide in assessment of neuroendocrine tumours. Clin Endocrinol. 2003;59: 565-73.

63. Even-Sapir E. Imaging of malignant bone involvement by morphologic, scintigraphic, and hybrid modalities. J Nucl Med. 2005;46:1356-67.

64. Davila D, Antoniou A, Chaudhry MA, editors. Evaluation of osseous metastasis in bone scintigraphy. Semin Nucl Med. 2015;45: $3-15$.

65. Azad GK, Taylor B, Rubello D, Colletti PM, Goh V, Cook GJ. Molecular and functional imaging of bone metastases in breast and prostate cancers: an overview. Clin Nucl Med. 2016;41:e44 50 .

66. Cook GJ, Azad GK, Goh V. Imaging bone metastases in breast cancer: staging and response assessment. J Nucl Med. 2016;57(Suppl 1):27s-33s.

67. Ritt P, Vija H, Hornegger J, Kuwert T. Absolute quantification in SPECT. Eur J Nucl Med Mol Imaging. 2011;38(Suppl1):S69-77.

68. Kuwert T. Skeletal SPECT/CT: a review. Clin Transl Imaging. 2014;2(6):505-17.

69. Jambor I, Kuisma A, Ramadan S, Huovinen R, Sandell M, Kajander S, et al. Prospective evaluation of planar bone scintigraphy, SPECT, SPECT/CT, 18F-NaF PET/CT and whole body $1.5 \mathrm{~T}$ MRI, including DWI, for the detection of bone metastases in high risk breast and prostate cancer patients: SKELETA clinical trial. Acta Oncol. 2016;55:59-67.

70. Horger M, Eschmann SM, Pfannenberg C, Vonthein R, Besenfelder H, Claussen C, et al. Evaluation of combined transmission and emission tomography for classification of skeletal lesions. AJR Amer J Roentgen. 2004;183:655-61.

71. Mahaletchumy T, AbAziz A. Incremental value of single-photon emission computed tomography-computed tomography for characterization of skeletal lesions in breast cancer patients. World J Nucl Med. 2017;16:303-10.

72. Zhao Z, Li L, Li F, Zhao L. Single photon emission computed tomography/spiral computed tomography fusion imaging for the diagnosis of bone metastasis in patients with known cancer. Skelet Radiol. 2010;39:147-9.

73. Zhang Y, Shi H, Gu Y, Xiu Y, Li B, Zhu W, et al. Differential diagnostic value of single-photon emission computed tomography/spiral computed tomography with Tc-99mmethylene diphosphonate in patients with spinal lesions. Nucl Med Commun. 2011;32:1194-200.

74. Zhang Y, Shi H, Li B, Cai L, Gu Y, Xiu Y. The added value of SPECT/spiral CT in patients with equivocal bony metastasis from hepatocellular carcinoma. Nuklearmedizin. 2015;54:255-61.

75. Palmedo H, Marx C, Ebert A, Kreft B, Ko Y, Türler A, et al. Whole-body SPECT/CT for bone scintigraphy: diagnostic value and effect on patient management in oncological patients. Eur J Nucl Med Mol Imaging. 2014;41:59-67.

76. Haraldsen A, Bluhme H, Røhl L, Pedersen EM, Jensen AB, Hansen EB, et al. Single photon emission computed tomography (SPECT) and SPECT/low-dose computerized tomography did not increase sensitivity or specificity compared to planar bone scintigraphy for detection of bone metastases in advanced breast cancer. Clin Physiol Funct Imaging. 2016;36:40-6. 
77. Fonager RF, Zacho HD, Langkilde NC, Fledelius J, Ejlersen JA, Haarmark C, et al. Diagnostic test accuracy study of (18)F-sodium fluoride PET/CT, (99m)Tc-labelled diphosphonate SPECT/CT, and planar bone scintigraphy for diagnosis of bone metastases in newly diagnosed, high-risk prostate cancer. Amer J Nucl Med Mol Imaging. 2017;7:218-27.

78. Sharma P, Jain TK, Reddy RM, Faizi NA, Bal C, Malhotra A, et al. Comparison of single photon emission computed tomography-computed tomography, computed tomography, single photon emission computed tomography and planar scintigraphy for characterization of isolated skull lesions seen on bone scintigraphy in cancer patients. Indian J Nucl Med. 2014;29:22-8.

79. Rager O, Nkoulou R, Exquis N, Garibotto V, Tabouret-Viaud C, Zaidi $\mathrm{H}$, et al. Whole-body SPECT/CT versus planar bone scan with targeted SPECT/CT for metastatic workup. BioMed Research Intern. 2017;2017.

80. Guezennec C, Keromnes N, Robin P, Abgral R, Bourhis D, Querellou S, et al. Incremental diagnostic utility of systematic double-bed SPECT/CT for bone scintigraphy in initial staging of cancer patients. Cancer Imaging. 2017;17:16.

81. Abikhzer G, Gourevich K, Kagna O, Israel O, Frenkel A, Keidar Z. Whole-body bone SPECT in breast cancer patients: The future bone scan protocol? Nucl Med Commun. 2016;37:247-53.

82. Kopka $\mathrm{K}$, Benešová $\mathrm{M}$, Bařinka $\mathrm{C}$, Haberkorn U, Babich J. GluUreido-Based Inhibitors of Prostate-Specific Membrane Antigen: Lessons Learned During the Development of a Novel Class of Low-Molecular-Weight Theranostic Radiotracers. J Nucl Med. 2017;58(Suppl 2):17S-26S.

83. Schwarzenboeck SM, Rauscher I, Bluemel C, Fendler WP, Rowe SP, Pomper MG, et al. PSMA ligands for PET imaging of prostate cancer. J Nucl Med. 2017;58:1545-52.

84. Hillier SM, Maresca KP, Lu G, Merkin RD, Marquis JC, Zimmerman CN, et al. 99mTc-labeled small-molecule inhibitors of prostate-specific membrane antigen for molecular imaging of prostate cancer. J Nucl Med. 2013;54:1369-76.

85. Hillier SM, Maresca KP, Femia FJ, Marquis JC, Foss CA, Nguyen $\mathrm{N}$, et al. Preclinical evaluation of novel glutamate-urea-lysine analogues that target prostate-specific membrane antigen as molecular imaging pharmaceuticals for prostate cancer. Cancer Res. 2009;69:6932-40.

86. Santos-Cuevas C, Davanzo J, Ferro-Flores G, Garcia-Perez FO, Ocampo-Garcia B, Ignacio-Alvarez E, et al. (99m)Tc-labeled PSMA inhibitor: Biokinetics and radiation dosimetry in healthy subjects and imaging of prostate cancer tumors in patients. Nucl Med Biol. 2017;52:1-6.

87. Frigerio B, Franssen G, Luison E, Satta A, Seregni E, Colombatti $\mathrm{M}$, et al. Full preclinical validation of the 123I-labeled anti-PSMA antibody fragment $\mathrm{ScFvD2B}$ for prostate cancer imaging. Oncotarget. 2017;8:10919.

88. Robu S, Schottelius M, Eiber M, Maurer T, Gschwend J, Schwaiger M, et al. Preclinical Evaluation and First Patient Application of 99mTc-PSMA-I\&S for SPECT Imaging and Radioguided Surgery in Prostate Cancer. J Nucl Med. 2017;58: 235-42.

89. Goffin KE, Joniau S, Tenke P, Slawin K, Klein EA, Stambler N, et al. Phase 2 study of $99 \mathrm{mTc}$-Trofolastat SPECT/CT to identify and localize prostate cancer in intermediate-and high-risk patients undergoing radical prostatectomy and extended pelvic LN dissection. J Nucl Med. 2017;58:1408-13.

90. Schmidkonz C, Cordes M, Beck M, Goetz TI, Schmidt D, Prante O, et al. SPECT/CT with the PSMA ligand 99mTc-MIP-1404 for whole-body primary staging of patients with prostate cancer. Clin Nucl Med. 2018;43:225-31.

91. Schmidkonz C, Hollweg C, Beck M, Reinfelder J, Goetz TI, Sanders JC, et al. (99m) Tc-MIP-1404-SPECT/CT for the detection of PSMA-positive lesions in 225 patients with biochemical recurrence of prostate cancer. Prostate. 2018;78:54-63.

92. Su H-C, Zhu Y, Ling G-W, Hu S-L, Xu X-P, Dai B, et al. Evaluation of $99 \mathrm{mTc}$-labeled PSMA-SPECT/CT imaging in prostate cancer patients who have undergone biochemical relapse. Asian J Androl. 2017;19:267.

93. Lawal IO, Ankrah AO, Mokgoro NP, Vorster M, Maes A, Sathekge MM. Diagnostic sensitivity of Tc-99m HYNIC PSMA SPECT/CT in prostate carcinoma: a comparative analysis with Ga-68 PSMA PET/CT. Prostate. 2017;77:1205-12.

94. Ostendorf B, Mattes-György K, Reichelt D, Blondin D, Wirrwar A, Lanzman R, et al. Early detection of bony alterations in rheumatoid and erosive arthritis of finger joints with high-resolution single photon emission computed tomography, and differentiation between them. Skelet Radiol. 2010;39:55-9.

95. Pipikos T, Kassimos D, Angelidis G, Koutsikos J. Bone Single Photon Emission/Computed Tomography in the Detection of Sacroiliitis in Seronegative Spondyloarthritis: A Comparison with Magnetic Resonance Imaging. Mol Imag Radionucl Therapy. 2017;26:101-8.

96. Querellou S, Arnaud L, Williams T, Breton S, Colin D, Le Roux $\mathrm{P}-\mathrm{Y}$, et al. Role of SPECT/CT compared with MRI in the diagnosis and management of patients with wrist trauma occult fractures. Clin Nucl Med. 2014;39:8-13.

97. Lee I, Budiawan H, Moon JY, Cheon GJ, Kim YC, Paeng JC, et al. The value of SPECT/CT in localizing pain site and prediction of treatment response in patients with chronic low back pain. $\mathrm{J}$ Korean Med Sci. 2014;29:1711-6.

98. Jain A, Jain S, Agarwal A, Gambhir S, Shamshery C, Agarwal A. Evaluation of Efficacy of Bone Scan With SPECT/CT in the Management of Low Back Pain. Clin J Pain. 2015;31:1054-9.

99. Russo VM, Dhawan RT, Baudracco I, Dharmarajah N, Lazzarino AI, Casey AT. Hybrid Bone SPECT/CT Imaging in Evaluation of Chronic Low Back Pain: Correlation with Facet Joint Arthropathy. World Neurosurg. 2017;107:732-8.

100. Rager O, Schaller K, Payer M, Tchernin D, Ratib O, Tessitore E. SPECT/CT in differentiation of pseudarthrosis from other causes of back pain in lumbar spinal fusion: report on 10 consecutive cases. Clin Nucl Med. 2012;37:339-43.

101. Sumer J, Schmidt D, Ritt P, Lell M, Forst R, Kuwert T, et al. SPECT/CT in patients with lower back pain after lumbar fusion surgery. Nucl Med Commun. 2013;34:964-70.

102. Hudyana H, Maes A, Vandenberghe T, Fidlers L, Sathekge M, Nicolai D, et al. Accuracy of bone SPECT/CT for identifying hardware loosening in patients who underwent lumbar fusion with pedicle screws. Eur J Nucl Med Mol Imaging. 2016;43:349-54.

103. Al-Riyami K, Gnanasegaran G, Van den Wyngaert T, Bomanji J. Bone SPECT/CT in the postoperative spine: a focus on spinal fusion. Eur J Nucl Med Mol Imaging. 2017;44:2094-104.

104. Cusi M, Saunders J, Van der Wall H, Fogelman I. Metabolic disturbances identified by SPECT-CT in patients with clinical diagnosis of sacroiliac joint incompetence. Eur Spine J. 2013;22: 1674-82.

105. Huellner MW, Strobel K. Clinical applications of SPECT/CT in imaging the extremities. Eur J Nucl Med Mol Imaging. 2014;41(Suppl 1):S50-8.

106. Krüger T, Hug U, Hüllner MW, Schleich F, Veit-Haibach P, von Wartburg U, et al. SPECT/CT arthrography of the wrist in ulnocarpal impaction syndrome. Eur J Nucl Med Mol Imaging. 2011;38:792-6.

107. Allainmat L, Aubault M, Noël V, Baulieu F, Laulan J, Eder V. Use of hybrid SPECT/CT for diagnosis of radiographic occult fractures of the wrist. Clin Nucl Med. 2013;38:e246-51.

108. Schleich FS, Schürch M, Huellner MW, Hug U, von Wartburg U, Strobel K, et al. Diagnostic and therapeutic impact of SPECT/CT 
in patients with unspecific pain of the hand and wrist. EJNMMI Res. 2012;2:53.

109. Huellner MW, Bürkert A, Schleich FS, Schürch M, Hug U, von Wartburg U, et al. SPECT/CT versus MRI in patients with nonspecific pain of the hand and wrist-a pilot study. Eur J Nucl Med Mol Imaging. 2012;39:750-9.

110. Huellner MW, Bürkert A, Strobel K, Lago MSP, Werner L, Hug U, et al. Imaging non-specific wrist pain: interobserver agreement and diagnostic accuracy of SPECT/CT, MRI, CT, bone scan and plain radiographs. PLoS One. 2013;8:e85359.

111. Schweizer T, Schiapparelli F-F, Rotigliano N, Rasch H, Amsler F, Hirschmann MT. Patterns of bone tracer uptake on SPECT-CT in symptomatic and asymptomatic patients with primary total hip arthroplasty. Eur J Nucl Med Mol Imaging. 2018;45:283-91.

112. Diederichs G, Hoppe P, Collettini F, Wassilew G, Hamm B, Brenner W, et al. Evaluation of bone viability in patients after girdlestone arthroplasty: comparison of bone SPECT/CT and MRI. Skelet Radiol. 2017;46:1249-58.

113. Al-Nabhani K, Michopoulou S, Allie R, Alkalbani J, Saad Z, Sajjan R, et al. Painful knee prosthesis: can we help with bone SPECT/CT? Nucl Med Commun. 2014;35:182-8.

114. Chew CG, Lewis P, Middleton F, van den Wijngaard R, Deshaies A. Radionuclide arthrogram with SPECT/CT for the evaluation of mechanical loosening of hip and knee prostheses. Ann Nucl Med. 2010;24:735-43.

115. Hirschmann MT, Schön S, Afifi FK, Amsler F, Rasch H, Friederich NF, et al. Assessment of loading history of compartments in the knee using bone SPECT/CT: A study combining alignment and $99 \mathrm{mTc}-\mathrm{HDP}$ tracer uptake/distribution patterns. J Orthop Res. 2013;31:268-74.

116. Barthassat E, Afifi F, Konala P, Rasch H, Hirschmann MT. Evaluation of patients with painful total hip arthroplasty using combined single photon emission tomography and conventional computerized tomography (SPECT/CT)-a comparison of semiquantitative versus $3 \mathrm{D}$ volumetric quantitative measurements. BMC Med Imaging. 2017;17:31.

117. Awengen R, Rasch H, Amsler F, Hirschmann M. Symptomatic versus asymptomatic knees after bilateral total knee arthroplasty: what is the difference in SPECT/CT? Eur J Nucl Med Mol Imaging. 2016;43:762-72.

118. Mathis DT, Hirschmann A, Falkowski AL, Kiekara T, Amsler F, Rasch $\mathrm{H}$, et al. Increased bone tracer uptake in symptomatic patients with ACL graft insufficiency: a correlation of MRI and SPECT/CT findings. Knee Surg Sports Traumatol Arthrosc. 2018;26(2):563-73.

119. Hirschmann MT, Mathis D, Rasch H, Amsler F, Friederich NF, Arnold MP. SPECT/CT tracer uptake is influenced by tunnel orientation and position of the femoral and tibial ACL graft insertion site. Int Orthop. 2013;37(2):301-9.

120. Bhure U, Roos JE, Pérez Lago MDS, Steurer I, Grünig H, Hug U, et al. SPECT/CT arthrography. Br J Radiol. 2018;91(1082): 20170635.

121. Biersack H, Wingenfeld C, Hinterthaner B, Frank D, Sabet A. SPECT-CT of the foot. Nuklearmedizin. 2012;51:26-31.

122. Ha S, Hong SH, Paeng JC, Lee DY, Cheon GJ, Arya A, et al. Comparison of SPECT/CT and MRI in diagnosing symptomatic lesions in ankle and foot pain patients: diagnostic performance and relation to lesion type. PLoS One. 2015;10(2):e0117583.

123. Chicklore S, Gnanasegaran G, Vijayanathan S, Fogelman I. Potential role of multislice SPECT/CT in impingement syndrome and soft-tissue pathology of the ankle and foot. Nucl Med Commun. 2013;34:130-9.

124. Knupp M, Pagenstert GI, Barg A, Bolliger L, Easley ME, Hintermann B. SPECT-CT compared with conventional imaging modalities for the assessment of the varus and valgus malaligned hindfoot. J Orthop Res. 2009;27:1461-6.
125. Singh VK, Javed S, Parthipun A, Sott AH. The diagnostic value of single photon-emission computed tomography bone scans combined with CT (SPECT-CT) in diseases of the foot and ankle. Foot Ankle Surg. 2013;19:80-3.

126. Agarwal KK, Mukherjee A, St A, Tripathi M, Bal C. Incremental value of single-photon emission computed tomography/computed tomography in the diagnosis of active condylar hyperplasia. Nucl Med Commun. 2017;38:29-34.

127. Erba PA, Israel O. SPECT/CT in infection and inflammation. Clin Transl Imaging. 2014;2:519-35.

128. Horger M, Eschmann SM, Pfannenberg C, Storek D, Dammann F, Vonthein R, et al. The value of SPET/CT in chronic osteomyelitis. Eur J Nucl Med Mol Imaging. 2003;30:1665-73.

129. Graute V, Feist M, Lehner S, Haug A, Müller PE, Bartenstein P, et al. Detection of low-grade prosthetic joint infections using $99 \mathrm{~m}$ Tc-antigranulocyte SPECT/CT: initial clinical results. Eur J Nucl Med Mol Imaging. 2010;37:1751-9.

130. Sathekge M, Garcia-Perez O, Paez D, El-Haj N, Kain-Godoy T, Lawal I, et al. Molecular imaging in musculoskeletal infections with 99m Tc-UBI 29-41 SPECT/CT. Ann Nucl Med. 2018;32:54 9.

131. Bar-Shalom R, Yefremov N, Guralnik L, Keidar Z, Engel A, Nitecki S, et al. SPECT/CT using 67Ga and $111 \mathrm{In}$-labeled leukocyte scintigraphy for diagnosis of infection. J Nucl Med. 2006;47: 587-94.

132. Fuster D, Solà $\mathrm{O}$, Soriano $\mathrm{A}$, Monegal $\mathrm{A}$, Setoain $\mathrm{X}$, Tomás $\mathrm{X}$, et al. A prospective study comparing whole-body FDG PET/CT to combined planar bone scan with $67 \mathrm{Ga}$ SPECT/CT in the diagnosis of spondylodiskitis. Clin Nucl Med. 2012;37:827-32.

133. Aslangul E, M'bemba J, Caillat-Vigneron N, Coignard S, Larger E, Boitard C, et al. Diagnosing diabetic foot osteomyelitis in patients without signs of soft tissue infection by coupling hybrid $67 \mathrm{Ga}$ SPECT/CT with bedside percutaneous bone puncture. Diabetes Care. 2013;36:2203-10.

134. Tamm AS, Abele JT. Bone and gallium single-photon emission computed tomography-computed tomography is equivalent to magnetic resonance imaging in the diagnosis of infectious spondylodiscitis: A retrospective study. Can Assoc Radiol J. 2017;68:41-6.

135. Jamar F, Buscombe J, Chiti A, Christian PE, Delbeke D, Donohoe $\mathrm{KJ}$, et al. EANM/SNMMI guideline for 18F-FDG use in inflammation and infection. J Nucl Med. 2013;54:647-58.

136. Filippi L, Schillaci O. Usefulness of hybrid SPECT/CT in 99mTcHMPAO-labeled leukocyte scintigraphy for bone and joint infections. J Nucl Med. 2006;47:1908-13.

137. Horger M, Eschmann SM, Pfannenberg C, Storek D, Vonthein R, Claussen CD, et al. Added value of SPECT/CT in patients suspected of having bone infection: preliminary results. Arch Orthop Trauma Surg. 2007;127:211-21.

138. Djekidel M, Brown RK, Piert M. Benefits of hybrid SPECT/CT for $111 \mathrm{In}$-Oxine-and Tc-99m-Hexamethylpropylene Amine Oxime-labeled leukocyte imaging. Clin Nucl Med. 2011;36: e50-e6.

139. Filippi L, Uccioli L, Giurato L, Schillaci O. Diabetic foot infection: usefulness of SPECT/CT for 99mTc-HMPAO-labeled leukocyte imaging. J Nucl Med. 2009;50:1042-6.

140. Heiba SI, Kolker D, Mocherla B, Kapoor K, Jiang M, Son H, et al. The optimized evaluation of diabetic foot infection by dual isotope SPECT/CT imaging. J Foot Ankle Surg. 2010;49:529-36.

141. Heiba S, Kolker D, Ong L, Sharma S, Travis A, Teodorescu V, et al. Dual-isotope SPECT/CT impact on hospitalized patients with suspected diabetic foot infection: saving limbs, lives, and resources. Nucl Med Commun. 2013;34:877-84.

142. Vouillarmet J, Morelec I, Thivolet C. Assessing diabetic foot osteomyelitis remission with white blood cell SPECT/CT imaging. Diabet Med. 2014;31:1093-9. 
143. La Fontaine J, Bhavan K, Lam K, Van Asten S, Erdman W, Lavery LA, et al. Comparison between Tc-99m WBC SPECT/CT and MRI for the diagnosis of biopsy-proven diabetic foot osteomyelitis. Wounds. 2016;28:271-8.

144. Lazaga F, Van Asten SA, Nichols A, Bhavan K, La Fontaine J, Oz OK, et al. Hybrid imaging with 99mTc-WBC SPECT/CT to monitor effect of therapy in diabetic foot osteomyelitis. Int Wound J. 2016;13:1158-60.

145. Vouillarmet J, Moret M, Morelec I, Michon P, Dubreuil J. Application of white blood cell SPECT/CT to predict remission after a 6 or 12 week course of antibiotic treatment for diabetic foot osteomyelitis. Diabetologia. 2017;60:2486-94.

146. Lazzeri E, Erba P, Perri M, Doria R, Tascini C, Mariani G. Clinical impact of SPECT/CT with In-111 biotin on the management of patients with suspected spine infection. Clin Nucl Med. 2010;35: $12-7$.

147. Kim HO, Na SJ, Oh SJ, Jung BS, Lee S-H, Chang JS, et al. Usefulness of adding SPECT/CT to $99 \mathrm{mTc}-$ hexamethylpropylene amine oxime (HMPAO)-labeled leukocyte imaging for diagnosing prosthetic joint infections. J Comput Assist Tomogr. 2014;38:313-9.

148. Bolouri C, Merwald M, Huellner MW, Veit-Haibach P, Kuttenberger J, Pérez-Lago M, et al. Performance of orthopantomography, planar scintigraphy, CT alone and SPECT/ CT in patients with suspected osteomyelitis of the jaw. Eur J Nucl Med Mol Imaging. 2013;40:411-7.

149. Sharma P, Agarwal KK, Kumar S, Singh H, Bal C, Malhotra A, et al. Utility of $99 \mathrm{~m}$ Tc-MDP hybrid SPECT-CT for diagnosis of skull base osteomyelitis: comparison with planar bone scintigraphy, SPECT, and CT. Jap J Radiol. 2013;31:81-8.

150. Chakraborty D, Bhattacharya A, Gupta AK, Panda NK, Das A, Mittal BR. Skull base osteomyelitis in otitis externa: The utility of triphasic and single photon emission computed tomography/ computed tomography bone scintigraphy. Indian journal of nuclear medicine: Ind. J Nucl Med. 2013;28:65.

151. Heiba SI, Stempler L, Sullivan T, Kolker D, Kostakoglu L. The ideal dual-isotope imaging combination in evaluating patients with suspected infection of pelvic pressure ulcers. Nucl Med Commun. 2017;38:129-34.

152. Lou L, Alibhai KN, Winkelaar GB, Turnbull RG, Hoskinson ME, Warshawski R, et al. 99mTc-WBC scintigraphy with SPECT/CT in the evaluation of arterial graft infection. Nucl Med Commun. 2010;31:411-6.

153. Khaja MS, Sildiroglu O, Hagspiel K, Rehm PK, Cherry KJ, Turba UC. Prosthetic vascular graft infection imaging. Clin Imaging. 2013;37:239-44.

154. Erba P, Leo G, Sollini M, Tascini C, Boni R, Berchiolli R, et al. Radiolabelled leucocyte scintigraphy versus conventional radiological imaging for the management of late, low-grade vascular prosthesis infections. Eur J Nucl Med Mol Imaging. 2014;41:35768.

155. Erba PA, Conti U, Lazzeri E, Sollini M, Doria R, De Tommasi $\mathrm{SM}$, et al. Added value of 99mTc-HMPAO-labeled leukocyte SPECT/CT in the characterization and management of patients with infectious endocarditis. J Nucl Med. 2012;53:1235-9.

156. Lauridsen TK, Iversen KK, Ihlemann N, Hasbak P, Loft A, Berthelsen AK, et al. Clinical utility of 18 F-FDG positron emission tomography/computed tomography scan vs. $99 \mathrm{~m}$ TcHMPAO white blood cell single-photon emission computed tomography in extra-cardiac work-up of infective endocarditis. Int J Card Imaging. 2017;33:751-60.

157. Litzler P-Y, Manrique A, Etienne M, Salles A, Edet-Sanson A, Vera P, et al. Leukocyte SPECT/CT for detecting infection of left-ventricular-assist devices: preliminary results. J Nucl Med. 2010;51:1044-8.
158. Erba PA, Sollini M, Conti U, Bandera F, Tascini C, De Tommasi $\mathrm{SM}$, et al. Radiolabeled WBC scintigraphy in the diagnostic workup of patients with suspected device-related infections. JACC Cardiovasc Imaging. 2013;6:1075-86.

159. Nowosinska E, Navalkissoor S, Quigley AM, Buscombe JR. Is there a Role for Gallium-67 Citrate SPECT/CT, in Patients with Renal Impairment or Who are Renal Transplant Recipients, in Identifying and Localizing Suspected Infection? World J Nucl Med. 2015;14:184-8.

160. Hung B-T, Wang P-W, Su Y-J, Huang W-C, Chang Y-H, Huang S$\mathrm{H}$, et al. The efficacy of $18 \mathrm{~F}-\mathrm{FDG}$ PET/CT and $67 \mathrm{Ga}$ SPECT/CT in diagnosing fever of unknown origin. Int J Infect Dis. 2017;62: $10-7$.

161. Woods A-M, Bolster AA, Han S, Poon F-W, Colville D, Shand J, et al. Dual-isotope subtraction SPECT-CT in parathyroid localization. Nucl Med Commun. 2017;38:1047-54.

162. Ciappuccini R, Morera J, Pascal P, Rame J-P, Heutte N, Aide N, et al. Dual-phase $99 \mathrm{mTc}$ sestamibi scintigraphy with neck and thorax SPECT/CT in primary hyperparathyroidism: a singleinstitution experience. Clin Nucl Med. 2012;37:223-8.

163. Mandal R, Muthukrishnan A, Ferris RL, de Almeida JR, Duvvuri U. Accuracy of early-phase versus dual-phase single photon emission computed tomography/computed tomography in the localization of parathyroid disease. Laryngoscope. 2015;125:1496-501.

164. Lavely WC, Goetze S, Friedman KP, Leal JP, Zhang Z, GarretMayer E, et al. Comparison of SPECT/CT, SPECT, and planar imaging with single-and dual-phase $99 \mathrm{mTc}$-sestamibi parathyroid scintigraphy. J Nucl Med. 2007;48:1084-9.

165. Patel C, Salahudeen H, Lansdown M, Scarsbrook A. Clinical utility of ultrasound and $99 \mathrm{mTc}$ sestamibi SPECT/CT for preoperative localization of parathyroid adenoma in patients with primary hyperparathyroidism. Clin Radiol. 2010;65:278-87.

166. Tokmak H, Demirkol MO, Alagöl F, Tezelman S, Terzioglu T. Clinical impact of SPECT-CT in the diagnosis and surgical management of hyper-parathyroidism. Int J Clin Exp Med. 2014;7: 1028-32.

167. Sandqvist P, Nilsson I-L, Grybäck P, Sanchez-Crespo A, Sundin A. SPECT/CT's advantage for preoperative localization of small parathyroid adenomas in primary hyperparathyroidism. Clin Nucl Med. 2017;42:e109-e14.

168. Koberstein W, Fung C, Romaniuk K, Abele JT. Accuracy of dual phase single-photon emission computed tomography/computed tomography in primary hyperparathyroidism: correlation with serum parathyroid hormone levels. Can Assoc Radiol J. 2016;67: 115-21.

169. Gayed IW, Kim EE, Broussard WF, Evans D, Lee J, Broemeling $\mathrm{LD}$, et al. The value of $99 \mathrm{mTc}$-sestamibi SPECT/CT over conventional SPECT in the evaluation of parathyroid adenomas or hyperplasia. J Nucl Med. 2005;46:248-52.

170. Krausz Y, Bettman L, Guralnik L, Yosilevsky G, Keidar Z, BarShalom R, et al. Technetium-99m-MIBI SPECT/CT in primary hyperparathyroidism. World J Surg. 2006;30:76-83.

171. Neumann D, Obuchowski N, Difilippo F. Preoperative 123I/ 99mTc-sestamibi subtraction SPECT and SPECT/CT in primary hyperparathyroidism. J Nucl Med. 2008;49:2012-9.

172. Pata G, Casella C, Magri GC, Lucchini S, Panarotto MB, Crea N, et al. Financial and clinical implications of low-energy CT combined with 99mTechnetium-sestamibi SPECT for primary hyperparathyroidism. Ann Surg Oncol. 2011;18:2555-63.

173. Pata G, Casella C, Besuzio S, Mittempergher F, Salerni B. Clinical appraisal of $99 \mathrm{mTechnetium-sestamibi} \mathrm{SPECT/CT} \mathrm{compared} \mathrm{to}$ conventional SPECT in patients with primary hyperparathyroidism and concomitant nodular goiter. Thyroid. 2010;20:1121-7.

174. Cheng Z, Zou S, Peng D, Zhang G, Zhu X. Prognostic Value of 99mTc-Sestamibi Parathyroid Scintigraphy in Predicting Future 
Surgical Eligibility in Patients With Asymptomatic Primary Hyperparathyroidism. Clin Nucl Med. 2018;43:151-4.

175. Suh YJ, Choi JY, S-j K, Chun IK, Yun TJ, Lee KE, et al. Comparison of 4D CT, ultrasonography, and 99mTc sestamibi SPECT/CT in localizing single-gland primary hyperparathyroidism. Otolaryngol Head Neck Surg. 2015;152:438-43.

176. Christakis I, Vu T, Chuang HH, Fellman B, Figueroa AMS, Williams MD, et al. The diagnostic accuracy of neck ultrasound, 4D-Computed tomographyand sestamibi imaging in parathyroid carcinoma. Eur J Radiol. 2017;95:82-8.

177. Zhen L, Li H, Liu X, Benjamin HG, Yan J, Yang J. The application of SPECT/CT for preoperative planning in patients with secondary hyperparathyroidism. Nucl Med Commun. 2013;34:439-44.

178. Chroustova D, Kubinyi J, Trnka J, Adamek S. The role of 99mTcMIBI SPECT/low dose CT with 3D subtraction in patients with secondary hyperparathyroidism due to chronic kidney disease. Endocr Regul. 2014;48:55-63.

179. Li P, Liu Q, Tang D, Zhu Y, Xu L, Sun X, et al. Lesion based diagnostic performance of dual phase 99m Tc-MIBI SPECT/CT imaging and ultrasonography in patients with secondary hyperparathyroidism. BMC Med Imaging. 2017;17:60.

180. Worsley DF, Alavi A, Aronchick J, Chen J, Greenspan R, Ravin C. Chest radiographic findings in patients with acute pulmonary embolism: observations from the PIOPED Study. Radiology. 1993;189:133-6.

181. Morrell N, Nijran K, Jones B, Biggs T, Seed W. The underestimation of segmental defect size in radionuclide lung scanning. J Nucl Med. 1993;34:370-5.

182. Meignan MA. Lung ventilation/perfusion SPECT: the right technique for hard times. J Nucl Med. 2002;43:648-53.

183. Roach PJ, Schembri GP, Baile L. V/Q scanning using SPECT and SPECT/CT. J Nucl Med. 2013;54(9):1588-96.

184. Jones SE, Wittram C. The indeterminate CT pulmonary angiogram: imaging characteristics and patient clinical outcome. Radiology. 2005;237:329-37.

185. Stein PD, Chenevert TL, Fowler SE, Goodman LR, Gottschalk A, Hales CA, et al. Gadolinium-enhanced magnetic resonance angiography for pulmonary embolism: a multicenter prospective study (PIOPED III). Ann Intern Med. 2010;152:434-43.

186. Bajc M, Bitzén U, Olsson B, De Sá VP, Palmer J, Jonson B. Lung ventilation/perfusion SPECT in the artificially embolized pig. J Nucl Med. 2002;43:640-7.

187. Collart J-P, Roelants V, Vanpee D, Lacrosse M, Trigaux J-P, Delaunois L, et al. Is a lung perfusion scan obtained by using single photon emission computed tomography able to improve the radionuclide diagnosis of pulmonary embolism? Nucl Med Commun. 2002;23:1107-13.

188. Leblanc M, Leveillée F, Turcotte E. Prospective evaluation of the negative predictive value of V/Q SPECT using 99mTc-Technegas. Nucl Med Commun. 2007;28:667-72.

189. Gutte H, Mortensen J, Jensen CV, Johnbeck CB, von der Recke P, Petersen CL, et al. Detection of pulmonary embolism with combined ventilation-perfusion SPECT and low-dose CT: head-tohead comparison with multidetector CT angiography. J Nucl Med. 2009;50:1987-92.

190. Miles S, Rogers KM, Thomas P, Soans B, Attia J, Abel C, et al. A comparison of single-photon emission CT lung scintigraphy and CT pulmonary angiography for the diagnosis of pulmonary embolism. Chest. 2009; 136:1546-53.

191. Bajc M, Neilly J, Miniati M, Schuemichen C, Meignan M, Jonson B. EANM guidelines for ventilation/perfusion scintigraphy. Eur J Nucl Med Mol Imaging. 2009;36:1356-70.

192. Roach PJ, Gradinscak DJ, Schembri GP, Bailey EA, Willowson KP, Bailey DL. SPECT/CT in V/Q scanning. Semin Nucl Med. 2010;40:455-66.
193. Ling I, Naqvi H, Siew T, Loh N, Ryan G. SPECT ventilation perfusion scanning with the addition of low-dose CT for the investigation of suspected pulmonary embolism. Intern Med J. 2012;42:1257-61.

194. Nezu K, Kushibe K, Sawabata N, Takahama M, Tojo T, Taniguchi $\mathrm{S}$, et al. Thoracoscopic lung volume reduction surgery for emphysema. Evaluation using ventilation-perfusion scintigraphy. Jpn J Thorac Cardiovasc Surg. 1999;47:267-72.

195. Komori K, Kamagata S, Hirobe S, Toma M, Okumura K, Muto M, et al. Radionuclide imaging study of long-term pulmonary function after lobectomy in children with congenital cystic lung disease. J Pediatr Surg. 2009;44:2096-100.

196. Xu J, Moonen M, Johansson $\AA$, Gustafsson A, Bake B. Quantitative analysis of inhomogeneity in ventilation SPET. Eur J Nucl Med. 2001;28:1795-800.

197. Pellegrino R, Biggi A, Papaleo A, Camuzzini G, Rodarte JR, Brusasco V. Regional expiratory flow limitation studied with Technegas in asthma. J Appl Physiol. 2001;91:2190-8.

198. Fujita J, Takahashi K, Satoh K, Okada H, Momoi A, Yamadori I, et al. Tc-99m Technegas scintigraphy to evaluate the lung ventilation in patients with oral corticosteroid-dependent bronchial asthma. Ann Nucl Med. 1999;13:247-51.

199. Sasaki Y, Imai T, Shinkai T, Ohishi H, Otsuji H, Uchida H, et al. Estimation of regional lung function in interstitial pulmonary disease using 99m Tc-technegas and 99m Tc-macroaggregated albumin single-photon emission tomography. Eur J Nucl Med. 1998;25:1623-9.

200. Nagao M, Murase K. Measurement of heterogeneous distribution on Technegas SPECT images by three-dimensional fractal analysis. Ann Nucl Med. 2002;16:369-76 20;50:554-621.

201. Hernando ML, Marks LB, Bentel GC, Zhou S-M, Hollis D, Das SK, et al. Radiation-induced pulmonary toxicity: a dose-volume histogram analysis in 201 patients with lung cancer. Int J Radiat Oncol Biol Phys. 2001;51:650-9.

202. Kong F-M, Hayman JA, Griffith KA, Kalemkerian GP, Arenberg $\mathrm{D}$, Lyons $\mathrm{S}$, et al. Final toxicity results of a radiation-dose escalation study in patients with non-small-cell lung cancer (NSCLC): Predictors for radiation pneumonitis and fibrosis. Int $\mathrm{J}$ Radiat Oncol Biol Phys. 2006;65:1075-86.

203. Mazeron R, Etienne-Mastroianni B, Pérol D, Arpin D, Vincent M, Falchero L, et al. Predictive factors of late radiation fibrosis: A prospective study in non-small cell lung cancer. Int J Radiat Oncol Biol Phys. 2010;77:38-43.

204. Roeder F, Friedrich J, Timke C, Kappes J, Huber P, Krempien R, et al. Correlation of patient-related factors and dose-volume histogram parameters with the onset of radiation pneumonitis in patients with small cell lung cancer. Strahlenther Onkol. 2010;186: 149-56.

205. Zhang J, Ma J, Zhou S, Hubbs JL, Wong TZ, Folz RJ, et al. Radiation-induced reductions in regional lung perfusion: $0.1-12$ year data from a prospective clinical study. Int J Radiat Oncol Biol Phys. 2010;76:425-32.

206. Woel RT, Munley MT, Hollis D, Fan M, Bentel G, Anscher MS, et al. The time course of radiation therapy-induced reductions in regional perfusion: a prospective study with $>5$ years of follow-up. Int J Radiat Oncol Biol Phys. 2002;52:58-67.

207. Munawar I, Yaremko BP, Craig J, Oliver M, Gaede S, Rodrigues $\mathrm{G}$, et al. Intensity modulated radiotherapy of non-small-cell lung cancer incorporating SPECT ventilation imaging. Med Phys. 2010;37:1863-72.

208. Hachamovitch R, Hayes S, Friedman JD, Cohen I, Shaw LJ, Germano $\mathrm{G}$, et al. Determinants of risk and its temporal variation in patients with normal stress myocardial perfusion scans: what is the warranty period of a normal scan? J Amer Coll Cardiol. 2003;41:1329-40. 
209. Ali I, Ruddy TD, Almgrahi A, Anstett FG, Wells RG. Half-time SPECT myocardial perfusion imaging with attenuation correction. J Nucl Med. 2009;50:554-62.

210. Mordi IR, Badar AA, Irving RJ, Weir-McCall JR, Houston JG, Lang CC. Efficacy of noninvasive cardiac imaging tests in diagnosis and management of stable coronary artery disease. Vasc Health Risk Manag. 2017;13:427-37.

211. van Dijk J, Mouden M, Ottervanger J, van Dalen J, Knollema S, Slump C, et al. Value of attenuation correction in stress-only myocardial perfusion imaging using CZT-SPECT. J Nucl Cardiol. 2017;24:395-401.

212. Schepis T, Gaemperli O, Koepfli P, Rüegg C, Burger C, Leschka $\mathrm{S}$, et al. Use of coronary calcium score scans from stand-alone multislice computed tomography for attenuation correction of myocardial perfusion SPECT. Eur J Nucl Med Mol Imaging. 2007;34:11-9.

213. Einstein AJ, Johnson LL, Bokhari S, Son J, Thompson RC, Bateman TM, et al. Agreement of visual estimation of coronary artery calcium from low-dose $\mathrm{CT}$ attenuation correction scans in hybrid PET/CT and SPECT/CT with standard Agatston score. J Amer Coll Cardiol. 2010;56:1914-21.

214. Budoff MJ, Dowe D, Jollis JG, Gitter M, Sutherland J, Halamert E, et al. Diagnostic performance of 64-multidetector row coronary computed tomographic angiography for evaluation of coronary artery stenosis in individuals without coronary artery disease: results from prospective multicenter ACCURACY (Assessment by Coronary Computed Tomographic Angiography of Individuals Undergoing Invasive Coronary Angiography) trial. J Amer Coll Cardiol. 2008;52:1724-32.

215. Miller JM, Rochitte CE, Dewey M, Arbab-Zadeh A, Niinuma H, Gottlieb I, et al. Diagnostic performance of coronary angiography by 64-row CT. New Engl J Med. 2008;359:2324-36.

216. Meijboom WB, Meijs MF, Schuijf JD, Cramer MJ, Mollet NR, van Mieghem CA, et al. Diagnostic accuracy of 64-slice computed tomography coronary angiography: a prospective, multicenter, multivendor study. J Amer Coll Cardiol. 2008;52:2135-44.

217. de Graaf FR, Schuijf JD, van Velzen JE, Kroft LJ, de Roos A, Reiber JH, et al. Diagnostic accuracy of 320-row multidetector computed tomography coronary angiography in the non-invasive evaluation of significant coronary artery disease. Eur Heart J. 2010;31:1908-15.

218. Dewey M, Zimmermann E, Deissenrieder F, Laule M, Dübel H-P, Schlattmann P, et al. Noninvasive coronary angiography by 320 row computed tomography with lower radiation exposure and maintained diagnostic accuracy: comparison of results with cardiac catheterization in a head-to-head pilot investigation. Circulation. 2009; 120:867-75.

219. van Velzen JE, de Graaf FR, Kroft LJ, de Roos A, Reiber JH, Bax JJ, et al. Performance and efficacy of 320-row computed tomography coronary angiography in patients presenting with acute chest pain: results from a clinical registry. Int J Card Imaging. 2012;28:865-76.

220. Schaap J, de Groot JA, Nieman K, Meijboom WB, Boekholdt SM, Post MC, et al. Hybrid myocardial perfusion SPECT/CT coronary angiography and invasive coronary angiography in patients with stable angina pectoris lead to similar treatment decisions. Heart. 2013;99:188-94.

221. Achenbach S, Marwan M, Ropers D, Schepis T, Pflederer T, Anders $\mathrm{K}$, et al. Coronary computed tomography angiography with a consistent dose below $1 \mathrm{mSv}$ using prospectively electrocardiogram-triggered high-pitch spiral acquisition. Eur Heart J. 2009;31:340-6.

222. Buechel RR, Husmann L, Herzog BA, Pazhenkottil AP, Nkoulou $\mathrm{R}$, Ghadri JR, et al. Low-dose computed tomography coronary angiography with prospective electrocardiogram triggering: feasibility in a large population. J Amer Coll Cardiol. 2011;57:332-6.
223. Filippi L, Schillaci O, Santoni R, Manni C, Danieli R, Simonetti G. Usefulness of SPECT/CT with a hybrid camera for the functional anatomical mapping of primary brain tumors by [Tc99m] tetrofosmin. Cancer Biother Radiopharm. 2006;21:41-8.

224. Filippi L, Santoni R, Nicolì P, Danieli R, Schillaci O. Intracranial tumors after radiation therapy: role of $99 \mathrm{mTc}$-tetrofosmin SPECT/ CT with hybrid camera. Cancer Biother Radiopharm. 2009;24: 229-35.

225. Liu H, Dong F, Meng Z, Zhang B, Tan J, Wang Y. Evaluation of Tourette's syndrome by $99 \mathrm{~m}$ Tc-TRODAT-1 SPECT/CT imaging. Ann Nucl Med. 2010;24:515-21.

226. Farid K, Habert M-O, Martineau A, Caillat-Vigneron N, Sibon I. CT nonuniform attenuation and TEW scatter corrections in brain Tc-99m ECD SPECT. Clin Nucl Med. 2011;36:665-8.

227. Ishii K, Hanaoka K, Okada M, Kumano S, Komeya Y, Tsuchiya $\mathrm{N}$, et al. Impact of $\mathrm{CT}$ attenuation correction by SPECT/CT in brain perfusion images. Ann Nucl Med. 2012;26:241-7.

228. Farid K, Petras S, Poullias X, Caillat-Vigneron N. Clinical impact of nonuniform CT-based attenuation correction brain perfusion SPECT/CT 99mTc-ECD. Clin Nucl Med. 2014;39:e343-e5.

229. Hsu C-C, Chang Y-H, Lin W-C, Tang S-W, Wang P-W, Huang Y$\mathrm{C}$, et al. The feasibility of using CT-guided ROI for semiquantifying striatal dopamine transporter availability in a hybrid SPECT/CT system. Sci World J. 2014;2014.

230. Kato H, Shimosegawa E, Fujino K, Hatazawa J. CT-Based Attenuation Correction in Brain SPECT/CT Can Improve the Lesion Detectability of Voxel-Based Statistical Analyses. PLoS One. 2016;11:e0159505.

231. Welz F, Sanders JC, Kuwert T, Maler J, Kornhuber J, Ritt P. Absolute SPECT/CT quantification of cerebral uptake of $99 \mathrm{mTc}-\mathrm{HMPAO}$ for patients with neurocognitive disorders. Nuklearmedizin. 2016;55:158-65.

232. Yokoyama K, Imabayashi E, Sumida K, Sone D, Kimura Y, Sato $\mathrm{N}$, et al. Computed-tomography-guided anatomic standardization for quantitative assessment of dopamine transporter SPECT. Eur J Nucl Med Mol Imaging. 2017;44:366-72.

233. Lapa C, Spehl TS, Brumberg J, Isaias IU, Schlögl S, Lassmann M, et al. Influence of CT-based attenuation correction on dopamine transporter SPECT with [123I] FP-CIT. Amer J Nucl Med Mol Imaging. 2015;5:278.

234. Mittal BR, Sood A, Shukla J, Vatsa R, Bhusari P, Shree R, et al. 99mTc-TRODAT-1 SPECT/CT imaging as a complementary biomarker in the diagnosis of parkinsonian syndromes. Nucl Med Commun. 2018;39:312-8.

235. Singh B, Kumar N, Sharma S, Watts A, Hazari PP, Rani N, et al. 99mTc-MDM brain SPECT for the detection of recurrent/remnant glioma - comparison with ceMRI and 18F-FLT PET imaging: initial results. Clin Nucl Med. 2015;40:e475-e9.

236. Feingold DL, Caliendo FJ, Chinn BT, Notaro JR, Oliver GC, Salvati EP, et al. Does hemodynamic instability predict positive technetium-labeled red blood cell scintigraphy in patients with acute lower gastrointestinal bleeding? A review of 50 patients. Dis Colon Rectum. 2005;48:1001-4.

237. Schillaci O, Spanu A, Tagliabue L, Filippi L, Danieli R, Palumbo $\mathrm{B}$, et al. SPECT/CT with a hybrid imaging system in the study of lower gastrointestinal bleeding with technetium-99m red blood cells. Quart J Nucl Med Mol Imaging. 2009;53:281-9.

238. Wang Z, Zhang G, Hao S, Zhang W, Zhang T, Zhang Z, et al. Technological value of SPECT/CT fusion imaging for the diagnosis of lower gastrointestinal bleeding. Genet Mol Res. 2015;14: 14947-55.

239. Dam HQ, Brandon DC, Grantham VV, Hilson AJ, Howarth DM, Maurer AH, et al. The SNMMI procedure standard/EANM practice guideline for gastrointestinal bleeding scintigraphy 2.0. J Nucl Med Tech. 2014;42:308-17. 
240. Grady E. Gastrointestinal bleeding scintigraphy in early 21st century. J Nucl Med. 2016;57:252-9.

241. Nadel HR. SPECT/CT in pediatric patient management. Eur J Nucl Med Mol Imaging. 2014;41(Suppl 1):S104-14.

242. Gelfand MJ, Lemen LC. PET/CT and SPECT/CT dosimetry in children: the challenge to the pediatric imager. Semin Nucl Med. 2007;37:391-8.

243. Brix G, Nekolla EA, Borowski M, Noßke D. Radiation risk and protection of patients in clinical SPECT/CT. Eur J Nucl Med Mol Imaging. 2014;41(Suppl 1):S125-36.

244. De Palma D, Nadel HR, Bar-Sever Z. Skeletal scintigraphy with SPECT/CT in benign pediatric bone conditions. Clin Transl Imaging. 2016;4:191-201.

245. Parisi MT, Iyer RS, Stanescu AL. Nuclear medicine applications in pediatric musculoskeletal diseases: the added value of hybrid imaging. Semin Musculoskelet Radiol. 2018;22:25-45.

246. Trout AT, Sharp SE, Anton CG, Gelfand MJ, Mehlman CT. Spondylolysis and beyond: value of SPECT/CT in evaluation of low back pain in children and young adults. Radiographics. 2015;35:819-34

247. Matesan M, Behnia F, Bermo M, Vesselle H. SPECT/CT bone scintigraphy to evaluate low back pain in young athletes: common and uncommon etiologies. J Orthop Surg Res. 2016;11:76.

248. Van den Wyngaert T, Strobel K, Kampen W, Kuwert T, Van der Bruggen W, Mohan $\mathrm{H}$, et al. The EANM practice guidelines for bone scintigraphy. Eur J Nucl Med Mol Imaging. 2016;43:172338.

249. Pelletier-Galarneau M, Martineau P, Gaudreault M, Pham X. Review of running injuries of the foot and ankle: clinical presentation and SPECT-CT imaging patterns. Amer J Nucl Med Mol Imaging. 2015;5:305.

250. Bar-Sever Z, Biassoni L, Shulkin B, Kong G, Hofman MS, Lopci $\mathrm{E}$, et al. Guidelines on nuclear medicine imaging in neuroblastoma. Eur J Nucl Med Mol Imaging. 2018;45:2009-24.

251. Sharp SE, Trout AT, Weiss BD, Gelfand MJ. MIBG in neuroblastoma diagnostic imaging and therapy. Radiographics. 2016;36: 258-78.

252. Francis GL, Waguespack SG, Bauer AJ, Angelos P, Benvenga S, Cerutti JM, et al. Management guidelines for children with thyroid nodules and differentiated thyroid cancer: the American Thyroid Association guidelines task force on pediatric thyroid cancer. Thyroid. 2015;25:716-59.

253. Avram AM. Radioiodine scintigraphy with SPECT/CT: an important diagnostic tool for thyroid cancer staging and risk stratification. J Nucl Med. 2012;53:754-64.

254. Parisi MT, Eslamy H, Mankoff D. Management of differentiated thyroid cancer in children: focus on the American Thyroid
Association pediatric guidelines. Semin Nucl Med. 2016;46: 147-64.

255. Spottswood SE, Pfluger T, Bartold SP, Brandon D, Burchell N, Delbeke D, et al. SNMMI and EANM practice guideline for meckel diverticulum scintigraphy 2.0. J Nucl Med Tech. 2014;42:163-9.

256. Parisi MT, Otjen JP, Stanescu AL, Shulkin BL. Radionuclide imaging of infection and inflammation in children: a review. Semin Nucl Med. 2018;48:148-65.

257. Milanesi O, Stellin G, Zucchetta P. Nuclear medicine in pediatric cardiology. Semin Nucl Med. 2017;47:158-69.

258. Hoggard N, Darwent G, Capener D, Wilkinson ID, Griffiths PD. The high incidence and bioethics of findings on magnetic resonance brain imaging of normal volunteers for neuroscience research. J Med Ethics. 2009;35:194-9.

259. Illes J, Kirschen M, Edwards E, Stanford L, Bandettini P, Cho M, et al. Incidental findings in brain imaging research. Science. 2006;311:783-4.

260. Berland LL, Silverman SG, Gore RM, Mayo-Smith WW, Megibow AJ, Yee J, et al. Managing incidental findings on abdominal CT: white paper of the ACR incidental findings committee. J Amer Coll Radiol. 2010;7:754-73.

261. Osman MM, Cohade C, Fishman EK, Wahl RL. Clinically significant incidental findings on the unenhanced CT portion of PET/CT studies: frequency in 250 patients. J Nucl Med. 2005;46:1352.

262. Lumbreras B, Donat L, Hernández-Aguado I. Incidental findings in imaging diagnostic tests: a systematic review. Br J Radiol. 2010;83:276-89.

263. Bruzzi JF, Truong MT, Marom EM, Mawlawi O, Podoloff DA, Macapinlac HA, et al. Incidental findings on integrated PET/CT that do not accumulate 18F-FDG. AJR. Am J Roentgenol. 2006; 187:1116-23.

264. Beatty JS, Williams HT, Aldridge BA, Hughes MP, Vasudeva VS, Gucwa AL, et al. Incidental PET/CT findings in the cancer patient: how should they be managed? Surgery. 2009;146:274-81.

265. Chopra A, Ford A, De Noronha R, Matthews S. Incidental findings on positron emission tomography/CT scans performed in investigation of lung cancer. Br J Radiol. 2012;85:e229-e37.

Publisher's note Springer Nature remains neutral with regard to jurisdictional claims in published maps and institutional affiliations. 